\title{
Conceptualising Binge Eating: A Review of the Theoretical and Empirical Literature
}

\author{
Amy L. Burton and Maree J. Abbott \\ School of Psychology, University of Sydney, New South Wales, Australia
}

\begin{abstract}
Binge eating is a distressing symptom common to bulimia nervosa (BN), anorexia nervosa binge/purge subtype (AN-BP) and binge-eating disorder (BED). Over the last 40 years, many attempts have been made to conceptualise this symptom in terms of its antecedents, function, triggers, consequences, and maintaining factors. Cognitive theories of binge eating have evolved as new evidence has emerged. This literature review summarises the main and most influential cognitive models of binge eating across different eating disorder presentations. Many theories have examined binge eating in the context of restriction or compensatory behaviours, as is often observed in cases of BN. Few theories have examined binge eating as it occurs in BED specifically. The long-term efficacy of cognitive behavioural therapy (CBT) treatment based on these models leaves much to be desired, and indicates that there may be maintaining factors of binge eating not addressed in the typical CBT treatment for eating disorders. More recent cognitive models of binge eating propose possible maintaining beliefs, but further study is required to validate these models. Suggestions for future research are presented.
\end{abstract}

Keywords: binge eating, eating disorders, model, theory, review

Despite a strong theoretical literature devoted to conceptualising eating disorders, particularly anorexia nervosa (AN) and bulimia nervosa (BN; see Pennesi \& Wade, 2016 for a review), there is very little to be found on the topic of theoretical models specifically addressing binge-eating disorder (BED). BED first appeared as an official diagnosis in the most recent edition of the Diagnostic and Statistical Manual of Mental Disorders (DSM-5; American Psychiatric Association [APA], 2013), accounting for why the theoretical literature in this area may still be in its infancy. Although much research is devoted to developing and trialling treatments for BED, this appears to be based on an understanding of eating disorders more generally, rather than on an evidence-based theoretical understanding of the underlying processes specific to BED. There are several influential models that describe binge eating pathology, usually in the presence of compensatory behaviours, as occurs for individuals with a diagnosis of BN or atypical eating disorders. However, very few studies address the processes unique to the presentation of BED. This review aims to comprehensively describe current understanding of the theoretical models used to formulate binge eating by presenting prominent theories of eating disorders that have

\footnotetext{
Address for correspondence: Amy Burton, The Brain and Mind Centre (M02F), School of Psychology, University of Sydney, 94-100 Mallett St, Camperdown NSW 2050, Australia.

Email: amy.burton@sydney.edu.au
} 
contributed to the current conceptualisation of binge eating, with a specific focus on the cognitive models of binge eating. This review will consider models that address binge eating pathology across different eating disorder presentations. Furthermore, this review seeks to summarise the commonalities and differences between the major psychological models for binge eating and to summarise the evidence in support of these models (refer to Tables 2 and 3 presented at the end of this review).

\section{Binge Eating}

Binge eating is a core feature of eating disorder presentations, common to $\mathrm{BN}, \mathrm{AN}$ (binge/purge subtype), BED and atypical eating disorders (APA, 2013). Binge eating is defined as eating large amounts of food in a discrete period of time, coupled with a sense of loss of control over one's eating and emotional distress (APA, 2013). Binge eating is associated with significant mental and physical health problems as well as impaired quality of life and social functioning (Wilfley, Wilson, $\&$ Agras, 2003). Binge eating is also associated with other mental disorders such as depression, anxiety, substance abuse, and personality disorders (Kessler et al., 2013; Picot \& Lilenfeld, 2003; Telch \& Stice, 1998; Wilfley et al., 2000; Wilfley et al., 2002). Additionally, binge eating is associated with chronic physical health conditions such as chronic pain, diabetes and hypertension (Kessler et al., 2013). Individuals who engage in binge eating are more likely to have a higher body mass index (BMI), being categorised as overweight or obese, than individuals who do not binge eat (Kessler et al., 2013). A longitudinal community study showed that the proportion of individuals with BED who met criteria for obesity increased by $17 \%$ over 5 years (Fairburn, Cooper, Doll, Norman, \& O'Connor, 2000).

Binge eating occurs along a continuum from normal to disordered eating and is present at a subthreshold level among the general community (Striegel-Moore et al., 2000). Reported rates of binge eating in the general community are increasing over time; a series of sequential community studies found that prevalence of objective binge eating increased from 3.1\% to 7.2\% between 1995 and 2005 (Hay, Mond, Buttner, \& Darby, 2008), and self-reported current weekly binge eating episode rates increased from $2.7 \%$ to $4.9 \%$ between 1998 and 2008 (Mitchison, Hay, Slewa-Younan, \& Mond, 2014). The DSM-5 (APA 2013) reported the prevalence of BN to be between 1-1.5\% in young females, being more prevalent than anorexia nervosa (AN), which has $0.4 \%$ prevalence in this group. While less is known about the prevalence of these eating disorders in males, the predicted prevalence is $\sim 20 \%$ of cases of $\mathrm{AN}$ and $\sim 16 \%$ of cases of BN (Hay et al., 2008). BED has a reported prevalence of $1.9 \%$ internationally (Kessler et al., 2013) and 2.3\% in Australia (Hay et al. 2008), with a predicted prevalence in males of 30-50\% of total cases of BED (APA, 2013; Hay et al., 2008; Kessler et al., 2013). There remains uncertainty in the literature regarding the key features that maintain binge-eating behaviour and whether there are substantial differences between key features, such as cognitions, for both subthreshold and diagnostic levels of binge eating, as well as how these key features differ between diagnostic groups (M.J. Cooper, 2005). Given the prevalence of binge eating both in the community and clinical populations, a sound understanding of the underlying mechanisms that maintain binge-eating behaviour is crucial for developing effective treatment models. 
In addition to medical treatments, such as pharmacology or bariatric surgery, and many alternative approaches to treatment for binge eating, such as Overeaters Anonymous (based on the Alcoholics or Narcotics Anonymous treatment approach) and hypnosis, there are a number of psychological treatments that address bingeeating behaviour, including cognitive behavioural therapy (CBT), schema therapy, interpersonal psychotherapy (IPT), behavioural weight loss (BWL), dialectical behavioural therapy (DBT), acceptance and commitment therapy (ACT), among others (Amianto, Ottone, Daga, \& Fassino, 2015; Brownley, Berkman, Sedway, Lohr, \& Bulik, 2007; Hay, 2013; Iacovino, Gredysa, Altman, \& Wilfley, 2012; Shapiro et al., 2007; Wilson, Grilo, \& Vitousek, 2007). A comprehensive series of systematic reviews summarise the treatment literature in this area. Shapiro et al. (2007) provide a summary of 47 randomised controlled trials (RCTs) examining treatments targeting BN, and Brownley et al. (2007) summarises 26 RCTs investigating treatments targeting BED published between 1980 and 2005. Both Shapiro et al. and Brownley et al. found evidence in support of medication and CBT treatments for $\mathrm{BN}$ and BED. However, both concluded that more evidence was needed regarding the long-term efficacy of these interventions. This was particularly the case with BED treatments, as the literature was still in its infancy at the time of the review. Following on from Shapiro et al. and Brownley et al., Hay (2013) systematically reviewed the eating disorders treatment literature of 2005 to 2012 . Hay noted that there was considerable progress in the evidence base for the treatment of eating disorders since the 2007 reviews; in particular, there was an increase in studies examining treatment efficacy for BED. Based on the results of her review, Hay concluded that CBT provided the best available treatment for $\mathrm{BN}$ and that although demonstrating promising results, further research on the treatment outcomes of BED was required. Amianto et al. (2015) summarise the results of 71 papers assessing treatment for BED published between 2008 and 2014. The results of this review suggested that multidisciplinary treatment programs appeared to provide the best treatment outcomes in terms of binge eating, abstinence, and weight management for people with BED. However, the authors recommend that the evidence suggests psychotherapeutic approaches based on CBT as a first-line treatment for binge eating. Amianto et al. concluded that future research needed to investigate the efficacy of BED treatments in larger sample sizes and with long-term follow-ups. Finally, Brownley et al. (2016) conducted a systematic review and meta-analysis on BED treatments. They concluded that the evidence supported CBT and some pharmacological treatments in reducing binge eating in people with BED; however, they noted that most of the included studies only measured outcome at the end of treatment and did not provide information on longer term outcomes. Overall, the findings of these reviews and the treatment studies to date highlight the need for long-term, follow-up studies of treatment outcomes for binge eating; in particular, for BED. This is particularly important considering that of those studies that provide longterm outcomes for binge-eating treatments, few studies have shown lasting effects of treatment (M.J. Cooper, 2005; Fairburn et al., 1995; Iacovino et al., 2012). It is widely agreed that for a treatment to target maintaining factors, it should be based upon an accurate theoretical model or formulation of the presenting problem. As such, several theories of eating disorders that account for binge-eating psychopathology have been proposed over the last four decades. The following section describes early theories of eating disorders that have influenced the major current cognitive models. 


\section{Early Models of Eating Disorders}

Bruch (1962) introduced the first modern theory of eating disorders, arguing that the patient's eating behaviours were a consequence of a psychological dysfunction that involved a disturbance of their body image, inability to interpret or respond to internal signals correctly (such as cues for hunger), and low self-esteem. Bruch argued that patients presenting with AN were engaging in behaviours that affected their body shape and weight to fulfil a need for control over their environment or themselves, which provided effective avoidance of interpersonal or intrapersonal situations that they perceived to be threatening (Bruch, 1975). Bruch acknowledged a role of societal pressure on young women to attain a certain physique and follow restrictive diets as possible triggers for AN (Bruch, 1977). Although Bruch's model focused on the restriction and over-exercising behaviours of AN, her work has greatly influenced subsequent psychological theories of eating disorders that are also relevant to binge-eating pathology.

Russell (1979) published early insights from his observations of individuals with $\mathrm{BN}$, describing the tendency of these individuals to have irresistible urges to engage in episodes of overeating, after which they would purge by vomiting or use of laxatives. He described these individuals as being preoccupied with thoughts of food, body shape, and weight, and to have a strong fear of gaining weight (Russell, 1979). Based on his observations, Russell hypothesised that the episodes of over-eating were meeting unfulfilled emotional needs for the individual. Following the episode, patients would purge or vomit in an attempt to avoid weight gain as a result of binge eating. He noted that in $\mathrm{BN}$ it appeared to be the episodes of overeating that were the primary symptom, and the purging/vomiting were secondary symptoms that occurred as a result of the over-eating, albeit symptoms that can have serious health consequences (e.g., electrolyte imbalances).

Thus, by the end of the 1970s, theories of eating disorders had focused on a fear of gaining weight and poor representation of one's body image as the driving factors for restrictive and compensatory behaviours observed in AN and BN (Williamson, White, York-Crowe, \& Stewart, 2004). Preoccupation with food, weight and body shape, and the idea that episodes of over-eating or binge eating were a reaction to emotional distress (Russell, 1979), remain relevant in current conceptualisations of eating disorders.

\section{Dietary Restraint Theory}

The influential dietary restraint theory proposed by Herman and Mack (1975) emphasises the role of dieting as a precipitating factor in the maintenance of binge eating, suggesting that restricting intake to the point of becoming chronically hungry made people more susceptible to overeating. Polivy and Herman (1985) presented evidence from the case study literature and animal studies that indicated that food restriction or dieting preceded the first binge-eating episode. On the basis of this evidence, they proposed that it is restrictive dieting that causes people to commence and continue binge eating. Polivy and Herman further suggested that people who binge eat are trapped in a cycle of restricting and then bingeing and then restricting, and so on. They postulated that people who engaged in restricted eating were then cognitively regulating their eating (as they were no longer relying on the physiological cues to eat). These individuals tended to engage in a 'black-and-white' thinking style in relation to food and eating whereby strict rules were applied dictating what foods were 
able to be eaten, in what quantities, and when. In doing so, they believed that this made the individual vulnerable to disinhibition, particularly when one of these strict rules was broken, which consequentially led to binge-eating episodes due to their 'all or nothing' cognitive style (Polivy \& Herman, 1985). Evidence that supports dietary restraint theory comes from prospective studies showing self-reported dieting could reliably predict future onset of binge eating in both non-clinical samples (Stice \& Agras, 1998; Stice, Killen, Hayward, \& Taylor, 1998; Stice, Presnell, \& Spangler, 2002) and samples of eating-disorder patients (Killen et al., 1996; Stice, 2002). Further evidence in support of the dietary restraint theory comes from a series of lab-based experiments that examine the phenomenon of counter-regulation (eating more after consuming a calorically rich food or meal) in restrained eaters (Polivy, 1996; Herman \& Polivy, 1988; Herman, Polivy, \& Esses, 1987; Knight \& Boland, 1989; Polivy, Heatherton $\&$ Herman, 1988). They measured disinhibited eating by calculating the amount of food (e.g., ice cream) consumed in a 'taste-testing' experiment, where participants were randomly allocated to consume a preload (i.e., a snack or meal high in calories such as a chocolate milkshake) prior to the 'taste test'. Overall, the results of these experiments show that non-dieters tend to regulate their intake and consume less food after a calorically high preload; however, dieters were found to eat more following the consumption of the preload relative to no preload eating, demonstrating a counter-regulatory response. In addition, Federoff, Polivy, and Herman (1997, 2003) compared the effect of food cues on desire to eat and cravings for food in restrained eaters versus unrestrained eaters. The results of this study found that restrained eaters were more responsive to food cues than unrestrained eaters; the restrained eaters ate significantly more of the cued food than the unrestrained eaters.

The dietary restraint model is commonly criticised for being too limited in its explanation of binge-eating pathology (Waller, 2002; Waters, Hill, \& Waller, 2001; Wilson, 2002). Although the evidence suggests that dietary restriction does play an important role in triggering and maintaining binge-eating behaviour, this model does not provide an explanation for binge episodes experienced by those who have not engaged in dietary restriction (McManus \& Waller, 1995). To understand and effectively treat binge eating, it is necessary to develop a more comprehensive model of the disordered behaviour that considers psychological as well as behavioural/environmental factors.

\section{Cognitive Models of Binge Eating}

Garner and Bemis (1982) provided an early cognitive model for AN that had its basis in Beck's cognitive model of depression (Beck, 1979). Garner and Bemis' theory places emphasis on the individual having distorted cognitions, such as the belief 'I must become thin'. They describe predisposing characteristics of AN patients as being introverted, emotionally sensitive, high achievers, with perfectionistic standards. They

172 suggest that these individuals become withdrawn and depressed, typically triggered by an external situation. They then suggest that the individual develops the belief, through family or society and the media, that losing weight will alleviate their distress, and so they begin engaging in behaviours such as dietary restriction or exercise in order to achieve this. Garner and Bemis propose that the initial success of weight loss leads to feelings of increased self-control, and the behaviour is reinforced by positive comments by others. This serves to reinforce their belief that 'thinness is paramount'. The individual then develops a fear of gaining weight, and as a result 
becomes preoccupied with losing weight and maintaining strict control over their eating increases. As a consequence, the disorder becomes self-maintaining (Garner $\&$ Bemis, 1982). Therefore, Garner and Bemis propose that, as in Beck's cognitive model of depression (Beck, 1979), distorted cognitions and beliefs are key maintaining factors in AN. Garner and Bemis' cognitive model of AN, together with the dietary restraint model, provided the theoretical framework for many of the major relevant cognitive theories of binge eating, including the widely cited cognitive-behavioural model of BN proposed by Fairburn, Cooper, and Cooper (1986).

\section{Cognitive-Behavioural Model of BN}

Fairburn et al. (1986) extended the ideas of Garner and Bemis' (1982) model for AN to also account for BN, emphasising the importance of body shape and weight as a key maintaining factor, and thoughts about food and eating as secondary to these (M. Cooper, Cohen-Tovée, Todd, Wells, \& Tovée, 1997; Fairburn, 2002a). Fairburn et al. described the cognitive processes present in $\mathrm{BN}$ to be very similar to those proposed for AN: a pervasive fear of fatness; the over-valuation of thinness and self-control; and a rigid, dichotomous style of thinking. This model emphasised the tendency for these individuals to judge their self-worth in relation to their eating, shape, and weight, and their control over these factors. This style of self-evaluation was thought to be paired with perfectionism, low self-esteem, and negative self-appraisals. Fairburn et al. propose that these beliefs and values about weight and shape lead to the observed behaviours of restricting caloric intake and either increased frequency or avoidance of weighing. Therefore, this model accounts for the binge-eating episodes that occur for individuals with $\mathrm{BN}$ as a consequence of their rigid, dichotomous thinking with regard to their eating. Their extreme concern about their weight and shape leads them to adopt strict and usually unrealistic rules about eating. Fairburn et al. proposed that when these individuals deviate from their self-imposed rules, they believe they have 'failed', 'lack self-control', and are 'weak'. As a result, Fairburn et al. posit that they abandon all control over their eating and commence a binge-eating episode. The binge-eating episodes are said to maintain the central cognitive disturbance of BN by acting to magnify the individual's concerns about their ability to control their eating, weight, and shape. This, in turn, is thought to further reinforce their engagement in dietary restraint and thereby increase the chance of future binge episodes. Refer to Figure 1 for a representation of Fairburn et al.'s model of BN. Thus, both the dietary restraint model as described by Herman and Mack (1975) and Fairburn et al.'s cognitive model for BN (Fairburn et al., 1986) present a vicious cycle whereby dietary restriction (driven by strict rules about eating) and binge-eating episodes (triggered when a dietary rule has been broken and/or chronic hunger as a result of the restriction) drive the disordered eating habits and related compensatory behaviours of those with $\mathrm{BN}$, mediated by beliefs about eating, weight, shape, and their control.

In addition to the components of the cognitive-behavioural model described above, Fairburn has also acknowledged that binge episodes are particularly likely to occur at times of low mood, with the emotional state thought to undermine the individual's ability to maintain their strict control over their eating (Fairburn, 2002a; Z. Cooper \& Fairburn, 2011). Fairburn proposed a role of binge eating in neutralising these negative mood states, suggesting that individuals were using binge eating as a form of mood modulation (Fairburn, 2002a). Fairburn has also highlighted that the role of compensatory behaviours such as self-induced vomiting, misuse of laxatives or 


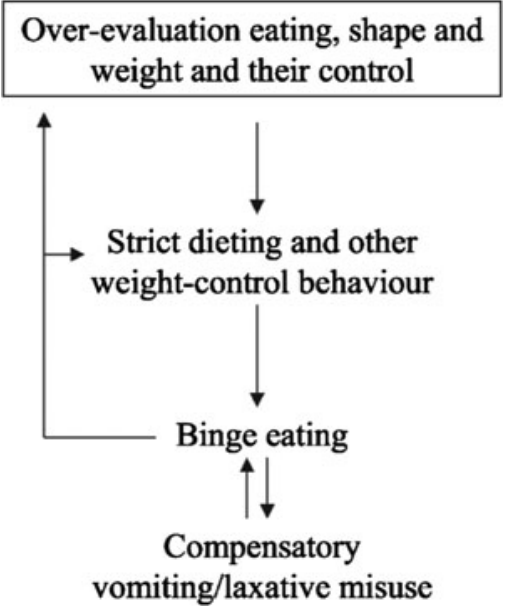

\section{FIGURE 1}

The cognitive behavioural theory of bulimia nervosa.

Note: Reproduced from Fairburn, Cooper, and Shafran (2003) with permission from the publisher.

diuretics, or intense exercise following a binge, suggesting that individuals with BN use compensatory behaviours to minimise the risk of weight gain following a binge episode (Fairburn, 2002a). As a result, one of the main barriers against overeating is removed and individuals become stuck in a vicious cycle of bingeing and purging, which further lowers self-esteem and further reinforces the binge-purge cycle (Fairburn, 2002a).

Fairburn, Marcus, and Wilson (1993) developed a cognitive-behavioural treatment program for BN (CBT-BN) based on the cognitive-behavioural model of binge eating. The National Institute for Clinical Excellence guidelines (NICE, 2004, as cited in Wilson \& Shafran, 2005) named this approach as the recommended first-line treatment for individuals with BN. Subsequently, this treatment approach has been found remission rates for binge eating in $\sim 30-50 \%$ of cases (Wilson et al., 2007). Agras, Walsh, Fairburn, Wilson, and Kraemer (2000) compared CBT treatment with interpersonal psychotherapy (IPT), a treatment originally developed for depression that has been modified for the treatment of BN (Fairburn, 2002b). Agras et al. completed a randomised control trial of $220 \mathrm{BN}$ patients who received treatment over a 20 -week period with a follow-up at 1 year post-treatment. At the end of the 20-week treatment, results found CBT to be superior to IPT at eliminating binge eating. However, at the 1 -year, post-treatment follow-up, there were no statistically significant differences in binge-eating abstinence between CBT and IPT where patients treated with CBT had

174 largely maintained their post-treatment gains and those with IPT had seen a continued reduction in their binge-eating frequency during the follow-up period (Agras et al., 2000). The results of this study demonstrated that CBT treatment provided a faster reduction in binge-eating behaviour compared to IPT, which is suggested to be due to the targeted nature of CBT. Agras et al. concluded that this result indicates a non-shared mechanism of action between these two treatments. Interestingly, despite observing reduced binge-eating frequency as a consequence of these two treatments, the core psychopathology of BN, such as shape and weight concerns, were found not 
to have been significantly reduced at the end of treatment (Agras et al., 2000). A follow-up study (Wilson, Fairburn, Agras, Walsh, \& Kraemer, 2002) that investigated the efficacy of the CBT treatment for BN found that a decrease in dietary restraint mediated the reduction in binge eating. They also found that mid-treatment measures of self-efficacy regarding eating behaviour, negative affect, and body shape and weight were also significantly associated with post-treatment outcome at 20 weeks (Wilson et al., 2002).

Although CBT-BN demonstrated some good outcomes, with $30-50 \%$ of BN patients treated with CBT having ceased binge eating and purging completely, a significant proportion remained symptomatic at the end of treatment (Wilson et al., 2002). When modified for the treatment of BED, this CBT approach has demonstrated $79 \%$ binge abstinence rates at post-treatment, superior to IPT (73\%; Wilfley et al., 2002). But again, there was no difference between CBT and IPT in the longterm maintenance of change, with approximately $40 \%$ of participants still engaging in binge eating at the 12-month follow-up: $41 \%$ and 39\% for CBT and IPT respectively (Wilfley et al., 2002). These less than ideal results indicate that CBT treatment, and the model that it is based on, requires further development, with the aim of appropriately understanding and addressing the factors that continue to maintain binge-eating pathology in approximately half the cases in these clinical populations.

\section{Escape Theory of Binge Eating}

Providing an alternative to dietary restraint theory and instead focusing on the link between negative affect and binge eating, Heatherton \& Baumeister (1991) proposed the escape theory of binge eating. In this theory, they suggest that individuals who binge eat do so in order to escape from self-awareness. They explain that these individuals hold high personal expectations about their weight and shape. They wish to be perceived favourably by others, are self-conscious, and assume that others are judging them. As a result, they develop a pattern of high self-awareness and self-criticism, and negative self-evaluation. These aversive perceptions of themselves lead to emotional distress, including anxiety and low mood. They wish to escape these negative cognitive experiences and attempt to achieve this by engaging in binge eating. The escape theory suggests that the binge-eating episodes provide relief from these negative internal experiences by focusing the individual's attention on simple actions and sensations. Therefore, the escape theory suggests that the key to overcoming binge eating is to learn other methods of coping with these negative experiences (Paxton $\&$ Diggens, 1997).

Blackburn, Johnston, Blampied, Popp, and Kallen (2006) assessed the applicability of escape theory to binge eating using structural equation modelling (SEM) in a nonclinical sample. Their results provided support for this model as they found that the escape model provided a good fit to the data. They found that in their sample, perfectionism strongly predicted aversive self-awareness, which was found to strongly predict negative affect, which significantly predicted avoidant coping strategies, which in turn strongly predicted binge eating (Blackburn et al., 2006). Providing further support for the escape theory, Engelberg, Steiger, Gauvin, and Wonderlich (2007) examined the relationship between negative affect, dissociative experiences, and binge eating in a sample of women who met criteria for an eating disorder that involved regularly engaging in binge eating or purging ( $\mathrm{BN}, \mathrm{BED}$, or an atypical eating disorder). 
The results of their study indicated that levels of negative affect and dissociation were significantly higher before a binge-eating episode compared to a meal or a snack (Engelberg et al., 2007). Although the evidence supporting the escape theory as a stand-alone explanation of binge-eating pathology is somewhat limited, it shares many similarities with other theories related to binge eating as a mechanism for distress tolerance and emotional regulation.

\section{Emotional Regulation Theory}

Lacey (1986) also viewed binge eating as serving the function of reducing awareness of aversive emotional states but also proposed that binge eating might provide a way of coping with stressors. In his model, Lacey described predisposing factors as being adverse family circumstances, family history of weight and eating problems, a focus on physical appearance, and reliance on external standards to judge self-worth. Lacey proposed that these predisposing factors led to impairments in the individual's interpersonal functioning and their sense of identity, resulting in a sense of ineffectiveness and loss of control over their own body. Lacey identified that binge eating is triggered by a significant life event, often relating to loss, sexual conflict, or significant life changes that causes the individual to be self-critical or experience negative affect. Lacey asserted that these individuals lack alternative coping skills, and thus when they experience significant stress or distress they turn to food (bingeing or restricting intake) to moderate their emotional state. Binge eating is said to calm aroused emotional states such as anger or distress, or to provide distraction from boredom or loneliness (Lacey, 1986). Thus, binge eating is maintained by the consequence of reducing negative affect (Lacey, 1986).

Waller (1993) argued that focusing on specific symptoms, or symptom clusters, in eating disorders is a more clinically useful approach to understand the processes of eating disorders due to the large variability between individual cases presenting with the same diagnosis. As such, he focused on understanding binge eating as a symptom. McManus and Waller (1995) acknowledge the evidence that suggests that binge eating is triggered by food cravings (Grilo, Shiffman, \& Carter-Campbell, 1994) or dieting (Polivy \& Herman, 1985), but they noted that this does not appear to be the case for all individuals who binge eat (Russell, 1979). They presented the argument that previous leading cognitive theories of BN (such as those of Fairburn et al., 1986) focused on the role of dietary restraint as a crucial trigger. However, McManus and Waller argue that this does not provide a sufficient explanation of the phenomenon of binge eating as it does not account for the binge episodes experienced by those who have not restricted. They also argued that the restraint theory does not provide an adequate explanation of the motivation to binge eat, nor the benefits experienced by the individual (Beebe, 1994). McManus and Waller reviewed the evidence that looked at emotional consequences of binge eating. They cited evidence from clinical observation

176 that reported that individuals experienced more stress, anxiety, and depression prior to the binge and that the negative affect is reduced during the binge, according to subjective reports (e.g., Chandarana \& Malla, 1989; Root \& Fallon, 1989). However, it has also been found that feelings of guilt, disgust and depression result after a binge episode, as well as anxiety about weight gain (McManus \& Waller, 1995). These feelings are then reduced by engaging in purging and compensatory behaviours that result in feelings of control and relief. However, following purging, the individual experiences depression and guilt. Thus, both bingeing and purging have been observed 
to reduce negative affect in the short term, but only insofar as they provide temporary relief or escape (McManus \& Waller, 1995).

There exists a substantial amount of experimental evidence supporting the emotional regulation model. For example, two independent laboratory experiments found that inducing a negative mood in women who had a diagnosis of BED resulted in a binge-eating episode and that a reduction in negative affect followed the binge episode (Agras \& Telch, 1998; Telch \& Agras, 1996). Indeed, a systematic review of 18 experimental studies examining the emotional regulation model in BED and obesity concluded that the results of the included studies supported the theory that negative emotion was an antecedent to binge eating for people with BED, and also that a short-term improvement in mood was experienced by participants following food intake in BED groups and also obesity (without BED) groups (Leehr et al., 2015).

Results from naturalistic and observational studies with clinical samples also provide support for the emotional regulation model. For example, the antecedents of binge eating were examined in a naturalistic study of women who engaged in binge eating. Results indicated that self-reported levels of negative affect and dissociation were elevated prior to the commencement of binge-eating episodes (Engelberg et al., 2007). Also, a study employing an ecological momentary assessment (EMA) method in a sample of individuals with a diagnosis of BED found that ratings for low mood were significantly higher (and ratings of positive mood significantly lower) on binge days compared to non-binge days (Munsch, Meyer, Quartier, \& Wilhelm, 2012). Munsch et al. (2012) also found that ratings of negative mood and tension increased significantly immediately prior to the binge-eating episode, and that subjective ratings of negative affect decreased and positive affect increased following a binge episode in people with BED. Munsch et al. concluded that these results indicated that binge eating in BED was triggered by a breakdown in emotional regulation attempts. In addition, studies have demonstrated a clear deficit in emotional regulation strategies in people with eating disorders compared to healthy controls (Lavender et al., 2015). Although deficits in emotional regulation ability have been observed across different eating disorder diagnostic groups (AN, BN, BED) and other psychological conditions such as borderline personality disorder and major depressive disorder (Lavender et al., 2015; Svaldi, Geirpenstroh, Tuschen-Caffier, \& Ehring, 2012), the results of Danner, Sternheim, and Evers (2014) demonstrate that the emotional regulation profile differs across the different eating disorder diagnostic groups. Interestingly, Danner et al. found that the emotional regulation profile of AN binge/purge subtype (AN-BP) was more similar to those of $\mathrm{BN}$ and $\mathrm{BED}$ than the $\mathrm{AN}$ restrictive type. However, it is important to note that some research has questioned the objectivity of the emotional regulation effect of binge eating; results from a meta-analysis of studies using EMA to assess negative affect before and after binge episodes did find that elevated levels of negative affect preceded binge-eating episodes; however, they did not find evidence that binge eating effectively reduced negative affect (Haedt-Matt $\&$ Keel, 2011). The authors of this meta-analysis note, however, that the studies included did not assess changes in affect during the binge-eating episodes and propose that it is possible that binge eating provides an immediate but time-limited, emotional regulation effect (Haedt-Matt \& Keel, 2011).

Based on the emotional regulation model, dialectical behaviour therapy (DBT) has been used to treat binge eating because of its role in enhancing emotional regulation (Safer, Telch, \& Agras, 2001a, 2001b). The efficacy of this type of treatment on reducing binge-eating frequency in individuals with BED (Telch, Agras, \& Linehan, 
2001) and BN (Safer et al., 2001b) also provides evidence for the validity of the emotional regulation model of binge eating. Although, like CBT, DBT has been shown to provide short-term reductions in binge eating ( $89 \%$ of participants abstinent from binge eating at the end of the 20-week treatment; Telch et al., 2001), these gains are not entirely maintained ( $56 \%$ had remained abstinent at the 6 -month followup; Telch et al., 2001), indicating that this treatment may also fail to address some important maintaining factors.

Building upon Lacey's (1986) formulation of binge eating, McManus and Waller (1995) provide a functional analysis of binge eating. They propose that people who binge eat have experienced particular predisposing factors that make that person more vulnerable to experiencing psychological difficulty. These predisposing factors include life dissatisfaction, a sense of ineffectiveness, low self-esteem (exacerbated by perfectionistic standards), a history of trauma, desire for control, and so on. They name two specific triggers of binge eating. The first trigger is food craving, believed to be resultant from dietary restriction. They account for the trigger of the dieting behaviour to be largely linked to the predisposing factors of need for control and societal pressures to be thin. The second trigger that they propose is the need to escape from aversive self-awareness and negative affect. This trigger is associated with many of the described predisposing factors such as low self-esteem and poor coping skills. They also described the consequences of binge eating as being an immediate reduction in negative affect and hunger, paired with longer term consequences of feelings of lack of control and anxiety about gaining weight, which serve to reinforce low self-esteem and increase effort to control their eating and weight further. In sum, McManus and Waller proposed that binge episodes are triggered by intolerable emotional states or hunger cues, that binge eating is maintained by the immediate effects of engaging in an episode - namely, reducing negative affect and food cravings - and that longer term effects, thought to exacerbate some of the original triggers, reinforce and maintain the cycle of behaviours.

\section{Schema Theory of Binge Eating}

Extending the theory of binge eating for emotional regulation to schema theory, Waller, Ohanian, Meyer, and Osman (2000) examined the function of binge eating in alleviating the negative affect that occurs following a negative core belief being triggered. Core beliefs, or schema-level cognitions, are defined as absolute, unconditional and dichotomous negative cognitions about oneself, others and the world (J.E. Young, 1994). They are believed to develop early in life as a relatively adaptive response to the child's environment. But, over time and with changed circumstances, they become maladaptive. Examples of these unconditional beliefs or schemas include fear of abandonment and beliefs about being inadequate, defective, unlovable, or a failure. When one or more of these negative core beliefs is triggered, self-esteem is

178 threatened and the individual may experience negative affect, such as low mood and anxiety, as a direct consequence.

Using the Young Schema Questionnaire (J.E. Young \& Brown, 1994), several studies have examined the core beliefs of individuals diagnosed with eating disorders (e.g., Leung, Thomas, \& Waller, 2000; Waller, Meyer, \& Ohanian, 2001; Waller et al., 2000). The results of these studies indicated that individuals with BED and $\mathrm{BN}$ experience significantly more pathological core beliefs than control participants. Certain schemas have been found to relate to particular eating disorder symptoms. 
Unoka, Tolgyes, Czobor, and Simon (2010) investigated the presence of early maladaptive schemas in people with diagnosed eating disorders. Their study found that particular schemas (emotional deprivation, abandonment, enmeshment, subjugation, and emotional inhibition) are associated with eating disorder behaviours (binge eating and purging) and there are differences in schema profiles across the different diagnostic groups (AN, AN-BP, BN). Across multiple studies, binge eating has been found to be associated with a number of early maladaptive schemas; specifically, emotional inhibition, abandonment, vulnerability to harm, emotional deprivation, defectiveness/shame, failure to achieve, insufficient self-control, mistrust/abuse, social undesirability, and social isolation (Pugh, 2015). In particular, the 'emotional inhibition' schema has been found to be a good predictor of binge-eating frequency in BN, BED and AN-BP (Waller, Dickson \& Ohanian, 2002; Waller et al., 2000; Waller et al., 2001). This schema relates to beliefs that emotions should not be experienced or expressed for fear of ridicule, shame, rejection, or feeling out of control. The schema model hypothesises that whenever the individual experiences strong feelings, they seek to inhibit their emotional response by either neutralising or avoiding their feelings. This is achieved by engaging in binge eating. In line with the theory of emotional regulation, episodes of binge eating function as a coping mechanism for dealing with what is perceived to be overwhelming negative affect (Waller et al., 2000).

Waller (2003) investigated the strength and type of core beliefs held by individuals with BED compared to BN or non-clinical controls, and then examined the relationship between the strength of certain core beliefs and the frequency of binge eating. The results of this study found that participants with either BN or BED demonstrated a higher level of pathological core beliefs than controls, but with a similar level to each other. This indicates that clinical participants experienced high levels of negative core beliefs, independent of their weight. Interestingly, BED participants endorsed different schemas on the Young Schema Questionnaire compared to the BN participants. Participants with a diagnosis of BED endorsed items pertaining to their inability to experience or express emotions, their inability to function independently, and their need to sacrifice their own needs for the needs for others more strongly than participants with BN, who endorsed items related to beliefs about abandonment more highly than those with BED. Another important finding was that the frequency of binge-eating episodes was associated with the strength of the core beliefs held, such that those who reported more episodes of binge eating were found to also have the highest levels of negative core beliefs. This particular finding was unique to the BED group; those in the $\mathrm{BN}$ group had high levels of negative cognitions regardless of the frequency of their binge episodes (Waller, 2003). These results provide further evidence that there are important differences between BED and $\mathrm{BN}$, and that it is not just the presence or absence of compensatory behaviours that separate the two diagnostic groups.

The evidence base for schema therapy in the treatment of binge eating is relatively limited, with only a few published studies examining the efficacy of schema-based therapy in this population (Masley, Gillanders, Simpson, \& Taylor, 2012; Pugh, 2015). A recent randomised controlled trial (RCT) assessed three different psychotherapies for the treatment of binge eating comparing schema therapy to CBT and an appetitefocused CBT treatment (McIntosh et al., 2016). The results of the study showed good outcomes for schema therapy in the treatment of binge eating, with significant reductions in binge frequency at the end of treatment; however, there were no significant differences in outcome between the three treatment modalities. McIntosh et al. 


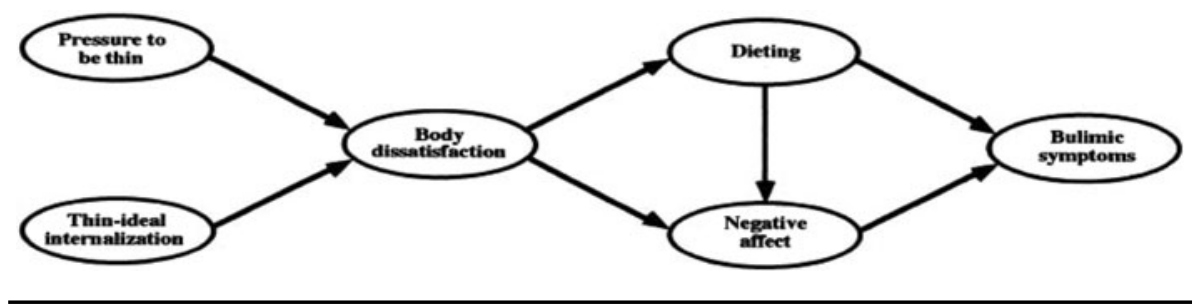

FIGURE 2

Dual pathway model.

Note: Reproduced from Stice (2001) with permission from the publisher.

(2016) concluded that schema therapy and appetite-focused CBT provided suitable alternatives to CBT in the treatment of binge eating. Although schema therapy has some evidence indicating promising results, more research is needed in this area to determine the long-term efficacy of schema-based therapy in the treatment of binge eating.

\section{Dual-Pathway Model}

Stice and Agras (1998) proposed the dual-pathway model of bulimic pathology. This model also considers the influence of emotional regulation, as well as socio-cultural and dietary factors. The dual-pathway model asserts that the socio-cultural influences of the thin ideal are internalised by the individual and lead to body dissatisfaction. Pressures to be thin, which come from family, peers and/or the media, compound this. The dual-pathway model suggests that the body dissatisfaction experienced by the individual leads to dieting and negative affect - two factors that increase the risk of the individual engaging in a binge-eating episode. Not only is there a direct link between body dissatisfaction and negative affect, but the model also proposed that the act of dieting itself leads to increased negative affect due to both the failures associated with attempted weight loss and the effect of caloric deprivation on mood. Dieting is thought to lead to binge eating as either a physiological response to the caloric deprivation (as in the dietary restraint model) or because breaking a 'strict rule' of a diet can result in disinhibited eating (as in the abstinence violation effect). Thus, the dual-pathway model proposes that binge eating occurs as a response to either negative affect, dieting or a combination of the two (Stice \& Agras, 1998). Refer to Figure 2 for a representation of the dual-pathway model proposed by Stice and Agras.

Stice (2001) tested the dual-pathway model using random regression growth curve models with a large community sample of adolescent women. Although the direct link between dieting and negative affect was found to be weak, the overall results of this analysis provided support for the dual-pathway model, supporting the model's hypotheses that pressure to be thin, thin-ideal internalisation, body dissatisfaction, dieting, and negative affect are risk factors for bulimia pathology (Stice, 2001). A separate study examined the contributions of the proposed mediators of dieting (or dietary restraint) and negative affect in the relationship between body dissatisfaction and binge eating, as defined in the dual-pathway model (Holmes, Fuller-Tyszkiewicz, Skouteris, \& Broadbent, 2015). Holmes et al.'s (2015) results provide support for the dual-pathway model, finding that the mediators of dietary restraint and negative affect made significant unique contributions to the body dissatisfaction-binge eating 
relationship, accounting for $23.83 \%$ of the shared variance. Multiple studies examining the dual-pathway model have found support for a link between negative affect and binge eating (refer also to the section on the emotional regulation model); however, there is less consensus in the literature regarding the link between dietary restraint and binge eating. Both a longitudinal study (Stice, Shaw, \& Nemeroff, 1998) and a cross-sectional study (van Strien, Engels, van Leuwe, \& Snoek, 2005) examining the fit of the dual-pathway model in a clinical sample did not find a evidence of a significant causal relationship between dietary restraint and binge eating.

Further evidence supporting the dual pathway model for BN comes from prevention/intervention studies and prospective studies from Stice and colleagues. A dissonance-based eating disorder prevention program was developed based on the dual pathway model (refer to Stice, Chase, Stormer, \& Appel, 2001). Long-term follow-up assessment of this prevention program provides strong evidence for the role of thin-ideal internalisation and body dissatisfaction in the development of eating disorder symptoms (Stice, Marti, Rohde, \& Shaw, 2011). Stice (2016) provides a review of multiple, large prospective studies and concludes that the risk factors of thin-ideal internalisation, perceived pressure to be thin, body dissatisfaction, dieting, and negative affect were found to be reliable predictors of later onset of BN. However, Stice (2016) did not identify any of the risk factors (or mediators) identified in the dual-pathway model to have predicted later onset of BED; the two studies identified that have investigated risk factors for BED (Stice et al., 2011 and Stice et al., 2015, as cited in Stice, 2016) found inconsistent results. Therefore, whether the dual-pathway model can be applied to BED remains unknown.

\section{Transdiagnostic Cognitive-Behavioural Model of Eating Disorders}

The important role of mood intolerance in maintaining binge eating pathology was acknowledged by Fairburn, Cooper, and Shafran (2003) in a revision of Fairburn's cognitive-behavioural model of BN. Fairburn et al. extended the focus of the model to incorporate additional maintaining mechanisms that had been found to interact with the original proposed core eating disorder mechanisms of weight, shape, and eating to create obstacles for change. In addition to acknowledging the role of mood intolerance, the maintaining mechanisms now included in the model concern the influence of clinical perfectionism, core low self-esteem and interpersonal difficulties (Fairburn et al., 2003). In the same article, Fairburn et al. also proposed that the revised model for BN could function as a 'transdiagnostic model' for eating disorders, as they believe that all eating disorders are maintained by similar psychopathological processes. This transdiagnostic model embraces a broader range of maintaining mechanisms and can be used to formulate not only BN, but also AN, BED and atypical eating disorders. Refer to Figure 3 for a diagram of the transdiagostic model.

An independent study evaluated the utility of this enhanced transdiagnostic cognitive behavioural model compared to Fairburn's original model (Fairburn et al., 1986) with a BN sample (Lampard, Byrne, McLean, \& Fursland, 2011). They found that both models provided a good fit to the data, but that the transdiagnostic model was able to account for a greater amount of variance in dietary restraint and binge eating than the original model. Similarly, Dalkanis et al. (2015) used structural equation modelling to evaluate and compare these two models in a large clinical binge-eating sample. The results of this study found that both models provided a good fit to the data. However, the transdiagnostic model was found to provide greater explanatory 


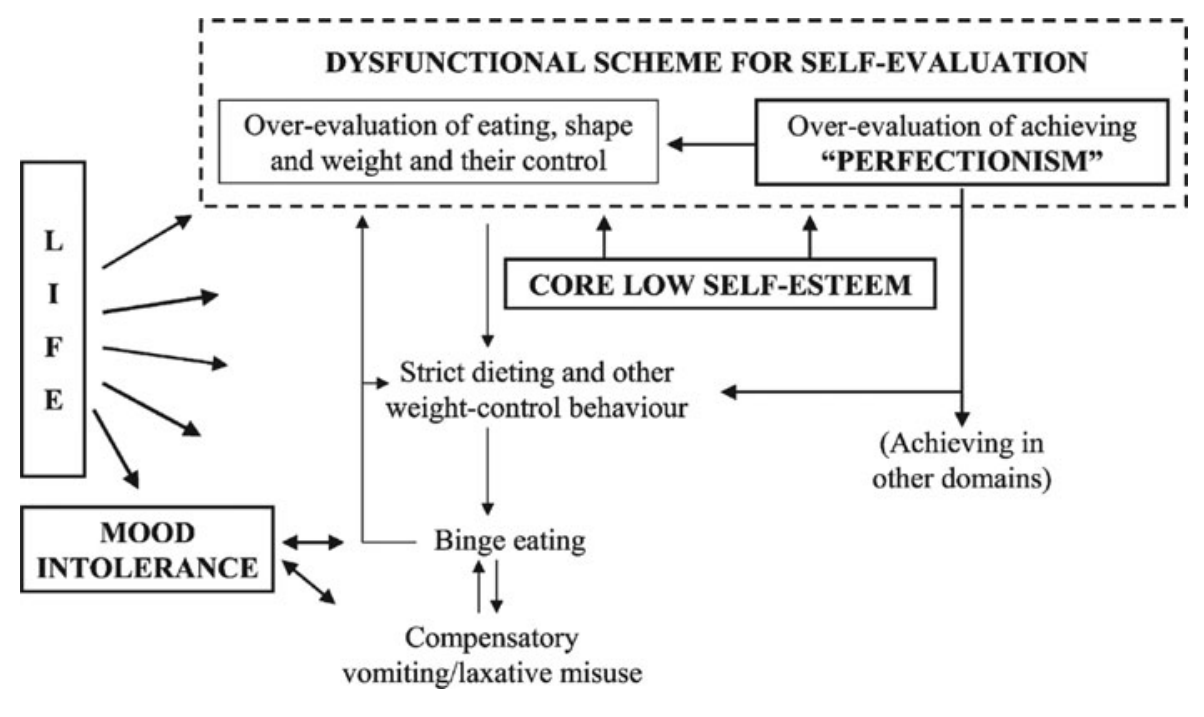

\section{FIGURE 3}

Transdiagnostic model.

Note: Reproduced from Fairburn, Cooper, \& Shafran (2003) with permission from the publisher.

power, accounting for a greater amount of variance in eating disorder symptoms than the original cognitive behavioural model. In a prospective study, three models of binge eating were evaluated and compared on their ability to fit the data (Allen, Byrne, \& McLean, 2012). The results of this study showed that Fairburn's original cognitive behavioural model for BN (Fairburn, 1986) did not provide a good fit to the data, but that the trandiagnostic model (Fairburn et al., 2003) and the dual-pathway model (Stice \& Agras, 1998) were more appropriate. However, the authors noted that although the fit statistics were acceptable, they were not excellent. They suggested that this result indicated that there may be additional variables involved that are not included in the transdiagnostic model or the dual-pathway model.

Based on the transdiagnostic model, Fairburn et al. (2008) developed an enhanced cognitive-behavioural transdiagnostic treatment program (CBT-E). Several clinical trials and RCTs have assessed the efficacy of CBT-E across different diagnostic groups. Fairburn et al. (2009) conducted a two-site trial of two versions of CBT-E, both involving 20 sessions of 50 minutes of individual psychotherapy. CBT-Ef was a 'focused' form of CBT-E in which session content is focused on pure eating disorder features (e.g., overconcern with shape and weight, dietary restriction, binge eating, and purging) and CBT-Eb which was a 'broad' form of CBT-E in which session content also addresses mood intolerance, perfectionism, poor self-esteem, and interpersonal functioning. The results of Fairburn et al.'s (2009) trial, and of a recent follow-up study by Fairburn et al. (2015) comparing CBT-Ef with interpersonal psychotherapy (IPT), are summarised in Table 1. Overall, a reduction in the number of participants reporting that they engaged in objective binge episodes (OBEs) occurs between pretreatment and post-treatment. This difference between pre- and post-OBEs is more pronounced for those participants receiving a CBT-E treatment than those receiving IPT. 
TABLE 1

Number of Participants Engaging in Objective Binge Eating Episodes (OBEs): Results From Two Papers Examining the Efficacy of CBT-E

\begin{tabular}{|c|c|c|c|c|c|c|}
\hline Paper & $\begin{array}{l}\text { Treatment } \\
\text { type }\end{array}$ & $\begin{array}{l}N \text { with } \\
\text { OBE at } \\
\text { pre- } \\
\text { treatment }\end{array}$ & $\begin{array}{l}N(\%) \text { with } \\
\text { OBE at } \\
\text { post- } \\
\text { treatment }\end{array}$ & $\begin{array}{l}N(\%) \text { with } \\
\text { OBE at } 20 \\
\text { weeks } \\
\text { FUP }\end{array}$ & $\begin{array}{l}N(\%) \text { with } \\
\text { OBE at } 40 \\
\text { weeks } \\
\text { FUP }\end{array}$ & $\begin{array}{l}N(\%) \text { with } \\
\text { OBE at } 60 \\
\text { weeks } \\
\text { FUP }\end{array}$ \\
\hline \multirow{2}{*}{$\begin{array}{l}\text { Fairburn } \\
\text { et al. (2009) }\end{array}$} & CBT-Ef & 49 & $26(53 \%)$ & $28(57 \%)$ & 24 (49\%) & $23(47 \%)$ \\
\hline & CBT-Eb & 52 & $18(35 \%)$ & $24(46 \%)$ & $22(42 \%)$ & $19(36.5 \%)$ \\
\hline \multirow{2}{*}{$\begin{array}{l}\text { Fairburn } \\
\text { et al. (2015) }\end{array}$} & CBT-Ef & 54 & $25(46 \%)$ & - & - & $19(35 \%)$ \\
\hline & IPT & 51 & 38 (75\%) & - & - & $20(39 \%)$ \\
\hline
\end{tabular}

However, the differences between treatment groups in the number of participants reporting engaging in OBEs at the 60-week follow-up is less pronounced, with over a third of all patients still engaging in OBEs following treatment.

Similar results were seen in an Australian-based open trial examining the efficacy of CBT-E for the treatment of eating disorders (Byrne, Fursland, Allen, \& Watson, 2011). This trial differed from Fairburn et al. (2009) as it included AN patients but did not include BED patients. Overall, $56.1 \%$ of patients were in full remission from their eating disorder at the end of treatment, with a further $10.6 \%$ in partial remission. For patients with BN, $50 \%$ of treatment completers were in full remission at the end of treatment, with a further $16.7 \%$ in partial remission at the end of treatment. There were significant differences between pre- and post-scores across a number of outcome measures, including improved quality of life and self-esteem, reduced depression, anxiety and stress scores, and a significant reduction in eating disorder psychopathology and symptoms. This included a significant reduction in the number of patients engaging in binge episodes between pre- and post-treatment. However, similar to the outcomes observed in Fairburn et al. (2009), out of 41 patients who were engaging in OBEs at pre-treatment, 15 (37\%) were still engaging in OBEs at the end of treatment.

In addition, two recent studies examining the efficacy of 20 individual sessions of focused CBT-Ef with patients with BN revealed mixed results. In Poulsen et al. (2014), 42\% of patients had ceased binge eating and purging at the end of CBT-E treatment and these gains were maintained at the 5-month and 24-month follow-up. Wonderlich et al. (2014) found a 76.3\% reduction in OBEs at the end of CBT-E treatment. However, only $22.5 \%$ of participants were symptom free (i.e., abstinent from both binge eating and purging) at the end of treatment and at the 4-month follow-up. In both studies it was observed that a significant majority of participants (58\% and $77.5 \%$ ) were still engaging in bulimic behaviours following 20 sessions of one-on-one CBT-Ef psychotherapy.

Given the relatively low long-term efficacy of the best available treatment for binge eating, there have been a number of studies that have investigated possible predictors of outcome of CBT for BN and BED. For example, duration of illness, severity of eating disorder symptoms, presence of comorbid psychological disorders (e.g., personality disorders or depressive disorders), and higher frequency of binge eating at pretreatment have been found to predict worse outcomes for CBT-E treatment (Cooper et al., 2016; Iacovino et al., 2012). In the treatment of BN, increased dietary restraint 
at pretreatment has found to be predictive of better treatment outcomes, whereas higher depression scores at pretreatment were indicative of poorer treatment outcomes (Accurso et al., 2016). In the treatment of BED, increased scores on drive for thinness and interoceptive awareness were found to predict better treatment outcomes, while binge-eating pathology and increased body dissatisfaction predicted poorer outcomes (Lammers, Vroling, Ouwens, Engels, \& Strien, 2015). In summary, when applied to a transdiagnostic sample, CBT-E demonstrates better long-term binge abstinence than its predecessor, CBT-BN. However, when the 'focused' form, CBT-Ef, is applied to a BN sample, over half of treated patients continue to engage in binge eating and purging behaviour at follow-up. The 'broad' version of CBT-Eb, with individualised components on mood tolerance, perfectionism, poor self-esteem and interpersonal functioning, seems to be the preferable form of CBT-E for treating binge eating. However, this outcome data still indicates that there may be components missing from the model that this treatment is based on that could be used to more effectively target, address, and eliminate binge-eating behaviour in patients.

\section{Integrated Cognitive Behavioural Model of Eating Disorders}

Williamson et al. (2004) also proposed a transdiagnostic model that integrates a variety of hypotheses developed since the 1970s. This model provides a good summary of the overall theoretical understanding of eating disorders. The authors reviewed the literature and incorporated the main evidence-based hypotheses into their integrated cognitive behavioural theory of eating disorders. They included the factors of body self-schema, cognitive biases, negative emotional reaction, binge eating, compensatory behaviours, and risk factors for eating disorders. The results can be observed in Figure 4.

This model summarises the psychological risk factors for eating disorders as including a fear of fatness, overconcern with body shape and/or weight, and perfectionism. Central to this integrated theory is the self-schema related to body, weight, or eating. This has been emphasised by many theorists who have noted the overconcern with body shape and weight can lead to a body self-schema whereby the individuals will judge themselves based on internal and external cues related to their body shape and/or weight. This model hypothesises that people with this type of body-related selfschema will have their cognitive biases activated by certain stimuli such as body- or food-related information, ambiguous stimuli, and situations that require the individual to engage in self-reflection. The model proposes that the activation of the cognitive biases leads to negative emotions such as anxiety, feeling fat, depression, anger, and self-loathing. The individual experiences these negative emotions as aversive and feels compelled to escape or avoid these emotions. This is achieved by engaging in purging behaviours, restrictive eating, or excessive exercise. In this model, binge eating is seen both as a way to escape or avoid the aversive emotional experience, and also as a consequence of the dietary restriction. Following a binge episode, the individual engages in a number of eating disordered behaviours to reduce the distress caused by binge eating and/or activation of the cognitive biases. These behaviours effectively reduce distress, which negatively reinforces the behaviours, confirms the individual's reliance on these avoidance behaviours, and serves to confirm their fear of fatness, overconcern with body shape and/or weight, internalisation of a thin ideal, and need for perfectionism or obessionality. Williamson et al. (2004) propose that this in turn serves to reinforce the body-related self-schema. 


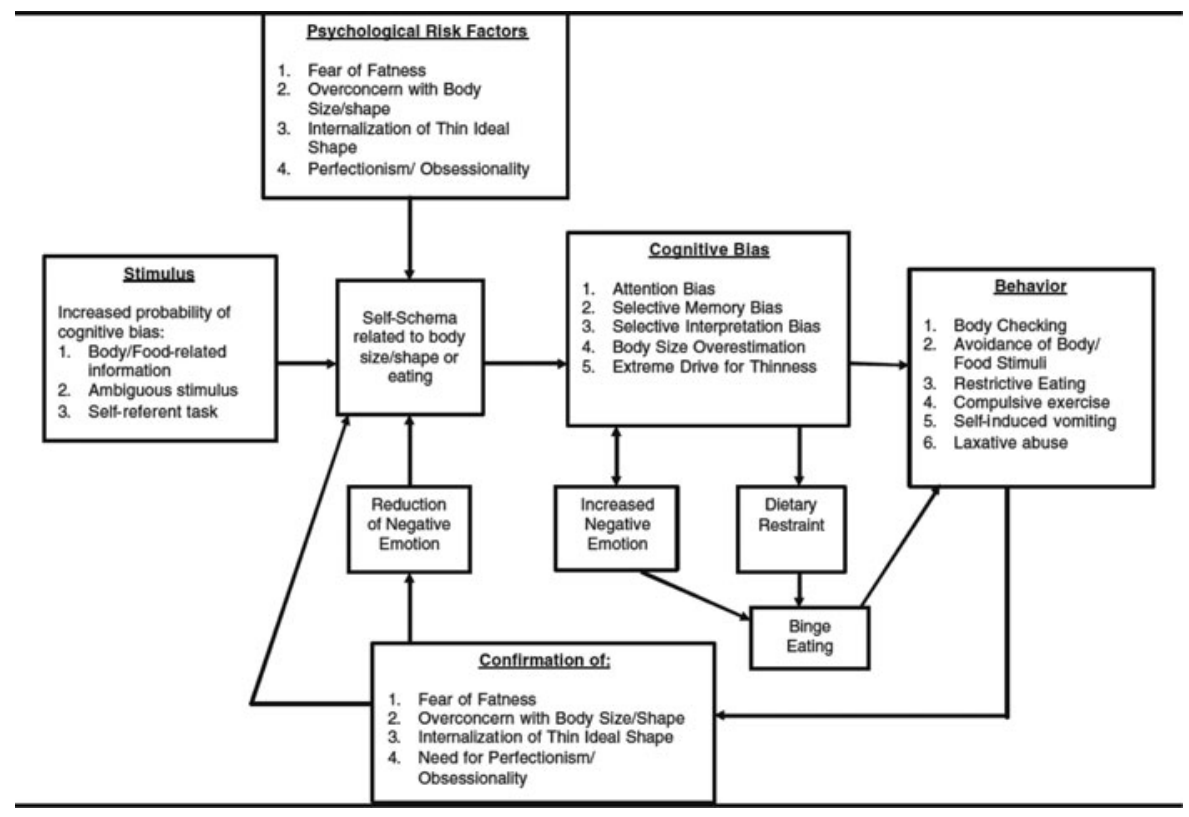

\section{FIGURE 4}

Integrated cognitive behavioural model of eating disorders.

Note: Reproduced from Williamson, White, York-Crowe, and Stewart (2004) with permission from the publisher.

The integrated model provides a good summary of much of the leading literature on this topic. It considers the theoretical contributions of dietary restraint theory, emotional regulation theory, the dual pathway model, schema theory, and core concepts that were proposed in Fairburn's cognitive behavioural model. The evidence for this model comes from the evidence that supports all the models that they have integrated (Williamson et al., 2004). This model has not been directly tested for its fit to the data, nor has there been any published treatment methods that are based on this integrated model. While this model encapsulates many processes that have been identified as contributing to eating disorder behaviour, none of the models summarised here so far have investigated whether individuals who binge eat have specific beliefs about food that may function to maintain binge-eating behaviour.

\section{Cognitive Model of BN}

M.J. Cooper, Wells, and Todd (2004) proposed a model for BN with the aim of addressing some shortfalls in the cognitive models proposed thus far. They based their model on the results of detailed semi-structured interviews with individuals meeting diagnostic criteria for $\mathrm{BN}$. In their interviews they collected information about the thoughts and feelings experienced by the individuals before, during, and after their most recent binge episode, as well as information regarding their beliefs, their early experiences, and their opinions on compensatory behaviours and dieting (data from these interviews are presented in M. Cooper, Todd, \& Wells, 1998). M.J. Cooper et al.'s (2004) model also drew heavily on much of the research summarised above, 
including the work of Bruch (1977), the escape theory of Heatherton and Baumeister (1991), and theories that describe binge eating as serving the function of coping with negative thoughts and feelings, such as in emotional regulation theory. M.J. Cooper et al. also drew inspiration from leading contemporary cognitive theories such as Beck's general schema theory (Beck, Freeman, \& Davis, 2006), J.E. Young's (1994) work on schema-driven processes, Padesky and Greenberger's (1995) work on the difference between core beliefs and underlying assumptions, and work by Wells (1993), which suggested that some disorders are maintained by conflicting and interacting beliefs about symptoms and functions of behaviours and unhelpful coping strategies.

The model proposed by M.J. Cooper et al. (2004) focuses on maintenance processes and developmental factors. The maintenance processes are presented as a cycle of behaviours that are driven by core beliefs and related meta-cognitive beliefs. M.J. Cooper et al. theorise that a binge-eating episode is triggered by a distressing event that activates a negative belief about the self as an acceptable person, such as 'I'm unlovable' or 'I'm a failure'. The activation of these negative self-appraisals is accompanied by feelings of anxiety, depression and/or guilt. The model suggests that these individuals engage in binge eating in order to cope with these emotions, and the process of eating reduces the intensity of the emotional states, which reinforces positive beliefs about eating (e.g., 'Eating helps me to feel better'). M.J. Cooper et al. describe a conflict experienced by those with $\mathrm{BN}$ as having both positive and negative beliefs about eating. This conflict is distressing, and so M.J. Cooper et al. argue that additional meta-cognitive beliefs about eating develop to reduce this distress. These beliefs are categorised as permissive beliefs (e.g., 'It's okay to binge') and beliefs related to loss of control (e.g., 'I cannot control my eating'). They suggest that it is the activation of permissive thoughts and thoughts of 'no control' that lead to a binge episode. The cycle continues as binge eating activates negative self-beliefs and negative thoughts about eating (e.g., 'I'll get fat') that lead to the behaviour of purging, which then serves to alleviate some of the distress caused by the binge-eating episode. M.J. Cooper et al. also describe a role for bodily sensations such as hunger in triggering a binge episode. They suggest that when hunger is a triggering factor, it activates thoughts of no control, which precipitates binge eating. Figure 5 presents a representation of this model.

M.J. Cooper et al. (2004) described the developmental factors that they believe contribute to the development of $\mathrm{BN}$. They identified that negative or traumatic experiences in early childhood or adolescence were found to lead to the development of dysfunctional beliefs, such as negative self-beliefs. Dieting is a method used by these individuals to cope with their negative self-beliefs; this is driven by the underlying assumptions that dieting will lead to acceptance by others or will allow them to accept themselves, as well as the development of negative beliefs about the consequences of gaining weight, which also serve to further reinforce the dieting behaviour.

M.J. Cooper et al.'s (2004) model is unique in the way in which it describes the role of positive, negative, and permissive metacognitive beliefs about eating in maintain186 ing binge eating. M.J. Cooper, Todd, Woolrich, Somerville, and Wells (2006) developed a measure to assess the maintaining metacognitive beliefs proposed in Cooper's cognitive model of BN (M. Cooper et al., 2004), the Eating Disorder Thoughts Questionnaire (EDTQ). This measure contained items that provided examples of positive, negative, and permissive beliefs about eating. The results of the discriminant validity analysis for this questionnaire found that the EDTQ could discriminate between people with a diagnosis of $\mathrm{AN}, \mathrm{BN}$, dieters, and controls. A different questionnaire was developed that aimed to assess the core negative self-beliefs hypothesised to maintain 


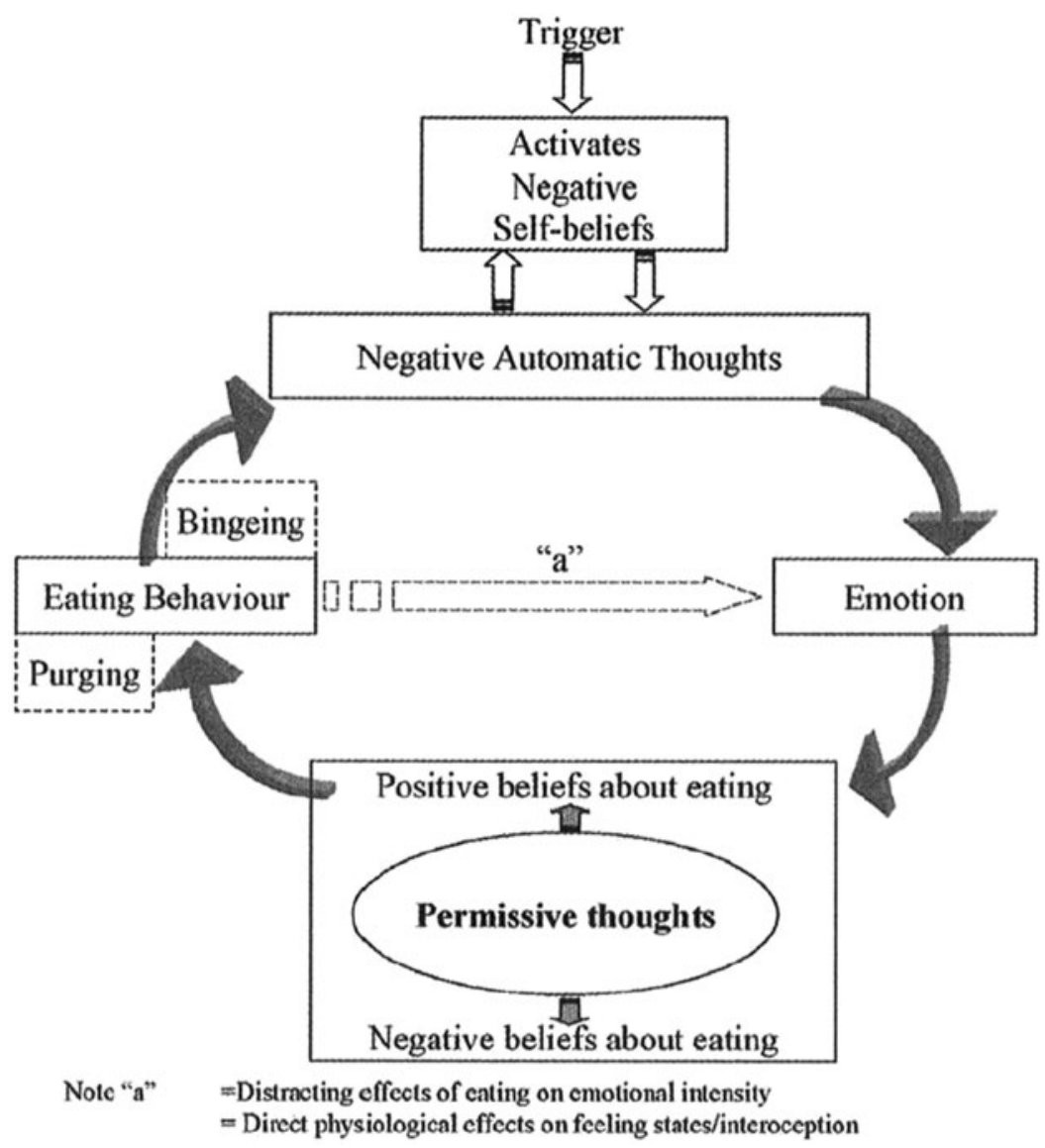

\section{FIGURE 5}

Cognitive model of bulimia nervosa.

Note: Reproduced from M.J. Cooper, Wells, and Todd (2004) with permission from the publisher.

BN in M.J. Cooper et al.'s (2004) model, the Eating Disorder Core Beliefs Questionnaire (ED-CBQ; Fairchild \& Cooper, 2010). In their preliminary findings on the validity of the ED-CBQ, Fairchild and Cooper (2010) found that items pertaining to self-loathing were significantly associated with eating disorder symptoms, both AN and BN. Young and Cooper (2013) investigated whether M.J. Cooper's cognitive model for bulimia could be applied to binge eating in a community sample. They assessed the presence of positive, negative, and permissive beliefs using the EDTQ (M.J. Cooper et al., 2006) and negative self-beliefs using the ED-CBQ (Fairchild \& Cooper, 2010). Their results indicated that these three categories of eating disorder thoughts (negative, positive, and permissive), as well as two negative beliefs (self-loathing and demanding/needing help and support) significantly predicted variance in binge-eating pathology in a community sample. Bergin and Wade (2012) tested the M.J. Cooper et al. model with a sample of individuals with $\mathrm{BN}$ and control participants. Consistent 
with the model, they found that negative self-beliefs were associated with negative affect, that negative affect was associated with both positive and negative thoughts about eating, that beliefs about eating were associated with eating behaviours, and that binge eating was associated with negative self-beliefs. They also found some inconsistencies with the model: they did not find an association between compensatory behaviour and negative self-beliefs, nor did they find any significant association of any behaviours with permissive thoughts. The authors noted that using a predominantly non-clinical sample may have limited the results of this study and they recommended more research was required to further develop and assess the model.

Based on this model, M. Cooper, Todd, and Wells (2000) developed a cognitive therapy self-help treatment manual for BN that could be used with or without the assistance of a therapist (i.e., guided self-help). Pritchard, Bergin, and Wade (2004) provided a preliminary evaluation of this treatment approach using a case series of 15 patients with $\mathrm{BN}$ who attended six 30-minute guided self-help (GSH) sessions with clinicians. Pritchard et al. found significant improvements in eating disorder symptoms and attitudes between pretreatment and post-treatment scores. This included binge eating, which was reduced by $73 \%$ at post-treatment, and by $74 \%$ at the 3 -month follow-up assessment. However, a third of patients still met clinical criteria for BN at the end of treatment and at the 3-month follow-up. Though such a significant reduction in binge-eating epsiodes is a promising result from a GSH program, it is likely that for this population, a more intensive, clinician-direction treatment approach would result in improved long-term outcomes.

M. Cooper, Todd, and Wells (2008) also developed a treatment manual for clinicians based on their cognitive model for BN (M.J. Cooper et al., 2004). They published preliminary findings of the results of an A-B single-case replication series (M. Cooper, Todd, Turner, \& Wells, 2007). Their study used a sample of three patients. All patients no longer met DSM-IV criteria for BN at the end of the 14-20 sessions of treatment. Two of the three were completely symptom free at the 6-month follow-up, and the third was symptom free at the 9-month follow-up. The findings of both Pritchard et al. (2004) and M. Cooper et al. (2007) are promising, but with significant limitations such as small sample sizes and no comparison groups. In order to thoroughly examine the efficacy of this treatment, a randomised controlled trial with a larger sample size should be undertaken.

Despite some promising preliminary results, empirical evidence supporting M.J. Cooper et al.'s (2004) theoretical understanding of binge eating is left wanting. Although this model is believed to provide a formulation of BED as well as BN, this model has not yet been validated with a clinical binge-eating group, nor with a group of individuals with a diagnosis of BED. In order to establish whether the model presented by M.J. Cooper et al. provides a sound and evidence-based model of binge eating in $\mathrm{BN}$ or $\mathrm{BED}$, it is important that the model is tested with a clinical sample. It would be useful for future research to compare fit statistics of the different leading models that are currently used to formulate binge-eating pathology such as Fairburn's transdiagnostic model (Fairburn et al., 2003), Williamson's integrated model (Williamson et al., 2004), and Cooper's cognitive model of BN (M.J. Cooper et al., 2004).

\section{Summary}

This review describes the most prominent theoretical models that offer a conceptualisation of binge eating across eating-disorder presentations. These models share many 


\section{TABLE 2}

Summary of Commonalities Across Models Included in this Review

\begin{tabular}{|c|c|c|c|c|c|c|c|c|c|c|}
\hline & $\begin{array}{l}\text { Dietary } \\
\text { restraint } \\
\text { model }\end{array}$ & $\begin{array}{l}\text { Cognitive } \\
\text { model of } \\
\text { BN }\end{array}$ & $\begin{array}{l}\text { Escape } \\
\text { theory }\end{array}$ & $\begin{array}{l}\text { Emotional } \\
\text { regulation } \\
\text { theory }\end{array}$ & $\begin{array}{l}\text { Functional } \\
\text { analysis } \\
\text { of binge } \\
\text { eating }\end{array}$ & $\begin{array}{l}\text { Schema } \\
\text { theory }\end{array}$ & $\begin{array}{l}\text { Dual- } \\
\text { pathway } \\
\text { model }\end{array}$ & $\begin{array}{l}\text { Transdiagnostic } \\
\text { cognitive- } \\
\text { behavioural } \\
\text { model of eating } \\
\text { disorders }\end{array}$ & $\begin{array}{l}\text { Integrated } \\
\text { cognitive } \\
\text { be- } \\
\text { havioural } \\
\text { model of } \\
\text { eating } \\
\text { disorders }\end{array}$ & $\begin{array}{l}\text { Cognitive } \\
\text { model of } \\
\text { BN }\end{array}$ \\
\hline $\begin{array}{l}\text { Dietary } \\
\text { restriction/restraint }\end{array}$ & $\sqrt{ }$ & $\sqrt{ }$ & & & $\sqrt{ }$ & & $\sqrt{ }$ & $\sqrt{ }$ & $\sqrt{ }$ & \\
\hline $\begin{array}{l}\text { Binge eating } \\
\text { (reinforcing cycle) }\end{array}$ & $\sqrt{ }$ & $\sqrt{ }$ & & $\sqrt{ }$ & & & & $\sqrt{ }$ & $\sqrt{ }$ & \\
\hline $\begin{array}{l}\text { Compensatory } \\
\text { behaviours } \\
\text { (reinforcing cycle) }\end{array}$ & $\sqrt{ }$ & $\sqrt{ }$ & & & & & & $\sqrt{ }$ & $\sqrt{ }$ & \\
\hline $\begin{array}{l}\text { Negative affect/Low } \\
\text { mood/Distress }\end{array}$ & & $\sqrt{ }$ & $\sqrt{ }$ & $\sqrt{ }$ & $\sqrt{ }$ & $\sqrt{ }$ & $\sqrt{ }$ & $\sqrt{ }$ & $\sqrt{ }$ & $\sqrt{ }$ \\
\hline $\begin{array}{l}\text { Thin-ideal } \\
\text { internalisation/Over- } \\
\text { evaluation of shape } \\
\text { and weight }\end{array}$ & & $\sqrt{ }$ & & & & & $\sqrt{ }$ & $\sqrt{ }$ & $\sqrt{ }$ & \\
\hline Pressure to be thin & & & & & $\sqrt{ }$ & & $\sqrt{ }$ & & & \\
\hline Body dissatisfaction & & & & & & & $\sqrt{ }$ & & $\sqrt{ }$ & \\
\hline $\begin{array}{l}\text { Mood intolerance/Poor } \\
\text { emotional regulation }\end{array}$ & & & $\sqrt{ }$ & $\sqrt{ }$ & $\sqrt{ }$ & $\sqrt{ }$ & & $\sqrt{ }$ & $\sqrt{ }$ & $\sqrt{ }$ \\
\hline Perfectionism & & $\sqrt{ }$ & & & $\sqrt{ }$ & & & $\sqrt{ }$ & $\sqrt{ }$ & \\
\hline
\end{tabular}


TABLE 2

Continued

self-esteem/Negative

core beliefs/Negative

self-schemas

Negative cognitions

about

eating/Overvaluation

of eating and its

control

Metacognitive beliefs

about eating and

food

Fear of gaining

weight/Fear of

fatness

Rigid thinking

style/Strict rules

about eating

Escape from

self-awareness

High self-awareness

Self-criticism

Integrated

cognitive

Transdiagnostic

be-

Dietary Cognitive

Functional

cognitive-

havioural

restraint model of

Emotional analysis

model

model of Escape regulation

of binge

$\begin{array}{ll}\text { Dual- } & \text { behavioural } \\ \text { pathway } & \text { model of eating }\end{array}$

model of

Cognitive

eating

model of

disorders

disorders

BN

$\sqrt{ } \sqrt{ }$

theory

$\sqrt{ }$

$\sqrt{ }$


TABLE 3

Summary of Evidence Base Across Models Included in this Review

\begin{tabular}{|c|c|c|c|c|c|c|c|c|}
\hline & $\begin{array}{l}\text { Dietary } \\
\text { restraint } \\
\text { model }\end{array}$ & $\begin{array}{l}\text { Cognitive- } \\
\text { behavioural } \\
\text { model of BN }\end{array}$ & $\begin{array}{l}\text { Escape } \\
\text { theory }\end{array}$ & $\begin{array}{l}\text { Emotional } \\
\text { regulation } \\
\text { theory }\end{array}$ & $\begin{array}{l}\text { Schema } \\
\text { theory }\end{array}$ & $\begin{array}{l}\text { Dual- } \\
\text { pathway } \\
\text { model }\end{array}$ & $\begin{array}{l}\text { Transdiagnostic } \\
\text { cognitive- } \\
\text { behavioural model } \\
\text { of eating disorders }\end{array}$ & $\begin{array}{l}\text { Cognitive } \\
\text { model of } \\
\text { BN }\end{array}$ \\
\hline $\begin{array}{l}\text { Evidence in support } \\
\text { of model's } \\
\text { applicability to } \\
\text { binge eating }\end{array}$ & + & + & $?$ & $?$ & $?$ & $?$ & + & $?$ \\
\hline $\begin{array}{l}\text { Treatment based on } \\
\text { model? }\end{array}$ & & $\begin{array}{l}\text { CBT-BN/ } \\
\text { CBT-BED }\end{array}$ & & DBT & $\begin{array}{l}\text { Schema } \\
\text { Therapy }\end{array}$ & & CBT-E & $\begin{array}{l}\text { Integrated } \\
\text { Metacogni- } \\
\text { tive and } \\
\text { Cognitive } \\
\text { Therapy }\end{array}$ \\
\hline $\begin{array}{l}\text { Evidence of efficacy } \\
\text { for treatment of } \\
\text { binge eating }\end{array}$ & & + & & + & $?$ & & + & $?$ \\
\hline
\end{tabular}

Note: $+=$ good evidence in support including treatment or experimental studies, $?=$ mixed evidence in support or further research required. 
commonalities, with most models being influenced by those that have come before them. Table 2 presents a summary of the main components of the models described in this review. Most of the models emphasise the role of poor emotional regulation skills and the presence of negative affect in precipitating binge eating. Also common across a majority of the models are negative core beliefs about the self and low self-esteem. Table 3 presents a summary of the evidence base for the models as described in this review. Overall, it is evident that the Fairburn CBT models have the most empirical evidence in support of them. However, it is important to note that this is in part due to the availability of research published investigating these models and treatments based on these models.

\section{Conclusion}

Binge eating is a common feature of eating disorders and it is associated with significant costs, such as comorbid mental and physical health problems, reduced quality of life, and poorer social functioning (Kessler et al., 2013; Wilfley et al., 2003). The majority of research assessing cognitive models of binge eating has focused on the role of restricting or dieting behaviour, negative affect, emotional regulation, low self-esteem, and preoccupations with body, shape, and weight. Most of these studies have been done in the context of $\mathrm{BN}$, thereby also examining the presence of compensatory behaviours. So far, CBT treatment based on these models has shown short-term success, but with disappointing long-term outcomes. This indicates that there may be maintaining factors that are not being addressed in the treatment. Further research should aim to contribute to theoretical and empirical knowledge by improving the understanding of the cognitive factors that are thought to maintain binge-eating behaviour. Improving the theoretical understanding of the maintaining factors involved in binge eating is the first step to improving evidence-based treatments for binge eating in both $\mathrm{BN}$ and BED. Some of the more recent theoretical developments, such as Waller (2003) and M.J. Cooper et al. (2004), have focused on examining maintaining beliefs or schemas that may be contributing to the frequency of post-treatment relapse observed in the binge-eating population. These models have shown promising preliminary evidence of their efficacy. However, further research needs to examine their relevance to clinical samples of both BN and BED patients. Treatment studies will especially need to examine whether a treatment model that addresses the proposed maintaining beliefs is effective in the long term, and whether such a treatment shows enhanced effectiveness relative to standard treatments. Given the high prevalence of binge eating, not only in eating disordered individuals but also in the general community, and the associated health costs to the individuals and the community, it is crucial that attempts be made to understand this prevalent problem and improve treatment outcomes for this population.

\section{Acknowledgments}

This research received no specific grant from any funding agency, commercial or not-for-profit sectors.

\section{Declaration of Interest}

None. 


\section{References}

Accurso, E.C., Wonderlich, S.A., Crosby, R.D., Smith, T.L., Klein, M.H., Mitchell, J.E., ... Peterson, C.B. (2016). Predictors and moderators of treatment outcome in a randomized clinical trial for adults with symptoms of bulimia nervosa. Journal of Consulting and Clinical Psychology, 84, $178-184$.

Agras, W.S., \& Telch, C.F. (1998). The effects of caloric deprivation and negative affect on binge eating in obese binge-eating disordered women. Behavior Therapy, 29, 491-503.

Agras, W.S., Walsh, B.T., Fairburn, C.G., Wilson, G.T., \& Kraemer, H.C. (2000). A multicenter comparison of cognitive-behavioral therapy and interpersonal psychotherapy for bulimia nervosa. Archives of General Psychiatry, 57, 459-466.

Allen, K.L., Byrne, S.M., \& McLean, N.J. (2012). The dual-pathway and cognitive-behavioural models of binge eating: Prospective evaluation and comparison. European Child $\mathbb{E}$ Adolescent Psychiatry, 21, 51-62.

American Psychiatric Association. (2013). Diagnostic and statistical manual of mental disorders (5th ed.). Washington, DC: Author.

Amianto, F., Ottone, L., Daga, G.A., \& Fassino, S. (2015). Binge-eating disorder diagnosis and treatment: A recap in front of DSM-5. BMC Psychiatry, 15, 70.

Beck, A.T. (1979). Cognitive therapy and the emotional disorders. London, UK: Penguin.

Beck, A.T., Freeman, A., \& Davis, D.D. (2006). Cognitive therapy of personality disorders. New York, NY: Guilford Press.

Beebe, D.W. (1994). Bulimia nervosa and depression: A theoretical and clinical appraisal in light of the binge - Purge cycle. British Journal of Clinical Psychology, 33, 259-276.

Bergin, J.L., \& Wade, T.D. (2012). A cross-sectional analysis of the cognitive model of bulimia nervosa. International Journal of Eating Disorders, 45, 776-786.

Blackburn, S., Johnston, L., Blampied, N., Popp, D., \& Kallen, R. (2006). An application of escape theory to binge eating. European Eating Disorders Review, 14, 23-31.

Brownley, K.A., Berkman, N.D., Sedway, J.A., Lohr, K.N., \& Bulik, C.M. (2007). Binge eating disorder treatment: A systematic review of randomized controlled trials. International Journal of Eating Disorders, 40, 337-348.

Bruch, H. (1962). Perceptual and conceptual disturbances in anorexia nervosa. Psychosomatic Medicine, 24, 187-194.

Bruch, H. (1975). Obesity and anorexia nervosa: Psychosocial aspects. Australasian Psychiatry, 9, 159-161.

Bruch, H. (1977). Psychological antecedents of anorexia nervosa. In R.A. Vigersky (Ed.), Anorexia nervosa (pp. 1-10). New York, NY: Basic Books.

Byrne, S.M., Fursland, A., Allen, K.L., \& Watson, H. (2011). The effectiveness of enhanced cognitive behavioural therapy for eating disorders: An open trial. Behaviour Research and Therapy, 49, 219 226.

Chandarana, P.C., \& Malla, A. (1989). Bulimia and dissociative states: A case report. The Canadian Journal of Psychiatry/La Revue canadienne de psychiatrie, 34, 137-139.

Cooper, M., Cohen-Tovée, E., Todd, G., Wells, A., \& Tovée, M. (1997). The eating disorder belief questionnaire: Preliminary development. Behaviour Research and Therapy, 35, 381-388.

Cooper, M., Todd, G., Turner, H., \& Wells, A. (2007). Cognitive therapy for bulimia nervosa: An A-B replication series. Clinical Psychology EO Psychotherapy, 14, 402-411.

Cooper, M.J., Todd, G., \& Wells, A. (1998). Content, origins, and consequences of dysfunctional beliefs in anorexia nervosa and bulimia nervosa. Journal of Cognitive Psychotherapy, 12, $213-230$.

Cooper, M., Todd, G., \& Wells, A. (2000). Bulimia nervosa: A cognitive therapy programme for clients. London, UK: Jessica Kingsley Publishers.

Cooper, M., Todd, G., \& Wells, A. (2008). Treating bulimia nervosa and binge eating: An integrated metacognitive and cognitive therapy manual. London, UK: Routledge. 
Cooper, M.J. (2005). Cognitive theory in anorexia nervosa and bulimia nervosa: Progress, development and future directions. Clinical Psychology Review, 25, 511-531.

Cooper, M.J., Todd, G., Woolrich, R., Somerville, K., \& Wells, A. (2006). Assessing eating disorder thoughts and behaviors: The development and preliminary evaluation of two questionnaires. Cognitive Therapy and Research, 30, 551-570.

Cooper, M.J., Wells, A., \& Todd, G. (2004). A cognitive model of bulimia nervosa. British Journal of Clinical Psychology, 43, 1-16.

Cooper, Z., Allen, E., Bailey-Straebler, S., Basden, S., Murphy, R., O'Connor, M.E., \& Fairburn, C.G. (2016). Predictors and moderators of response to enhanced cognitive behaviour therapy and interpersonal psychotherapy for the treatment of eating disorders. Behaviour Research and Therapy, 84, 9-13.

Cooper, Z., \& Fairburn, C.G. (2011). The evolution of 'enhanced' cognitive behavior therapy for eating disorders: Learning from treatment nonresponse. Cognitive and Behavioral Practice, 18, 394-402.

Dakanalis, A., Carrà, G., Calogero, R., Zanetti, M.A., Gaudio, S., Caccialanza, R., ... Clerici, M. (2015). Testing the cognitive-behavioural maintenance models across DSM-5 bulimic-type eating disorder diagnostic groups: a multi-centre study. European Archives of Psychiatry and Clinical Neuroscience, 265, 663-676.

Danner, U.N., Sternheim, L., \& Evers, C. (2014). The importance of distinguishing between the different eating disorders (sub) types when assessing emotion regulation strategies. Psychiatry Research, 215, 727-732.

Engelberg, M.J., Steiger, H., Gauvin, L., \& Wonderlich, S.A. (2007). Binge antecedents in bulimic syndromes: An examination of dissociation and negative affect. International Journal of Eating Disorders, 40, 531-536.

Fairburn, C.G. (2002a). Cognitive-behavioural therapy for bulimia nervosa. In C.G. Fairburn \& K.D. Brownell (Eds.), Eating disorders and obesity: A comprehensive handbook (pp. 303-307). New York, NY: Guilford Press.

Fairburn, C.G. (2002b). Interpersonal psychotherapy for eating disorders. In C.G. Fairburn \& K.D. Brownell (Eds.), Eating disorders and obesity: A comprehensive handbook (pp. 320-324). New York, NY: Guilford Press.

Fairburn, C.G., Bailey-Straebler, S., Basden, S., Doll, H.A., Jones, R., Murphy, R., O'Connor, M.E. \& Cooper, Z. (2015). A transdiagnostic comparison of enhanced cognitive behaviour therapy (CBT-E) and interpersonal psychotherapy in the treatment of eating disorders. Behaviour Research and Therapy, 70, 64-71.

Fairburn, C.G., Cooper, Z., \& Cooper, P.J. (1986). The clinical features and maintenance of bulimia nervosa. In K.D. Brownell \& J.P. Foreyt (Eds.), Handbook of eating disorders: Physiology, psychology and treatment of obesity, anorexia and bulimia (pp. 389-404). New York, NY: Basic Books.

Fairburn, C.G., Cooper, Z., Doll, H.A., Norman, P., \& O'Connor, M. (2000). The natural course of bulimia nervosa and binge eating disorder in young women. Archives of General Psychiatry, 57, 659-665.

Fairburn, C.G., Cooper, Z., Doll, H.A., O'Connor, M.E., Bohn, K., Hawker, D.M., Wales, J.A. \& Palmer, R.L. (2009). Transdiagnostic cognitive-behavioral therapy for patients with eating disorders: A two-site trial with 60-week follow-up. American Journal of Psychiatry, 166, 311-319.

Fairburn, C.G., Cooper, Z., \& Shafran, R. (2003). Cognitive behaviour therapy for eating disorders: A 'transdiagnostic' theory and treatment. Behaviour Research and Therapy, 41, 509-528.

Fairburn, C.G., Cooper, Z., Shafran, R., Bohn, K., Hawker, D.M., Murphy, R., \& Straebler, S. (2008). Enhanced cognitive behavior therapy for eating disorders: The core protocol. In C.G. Fairburn (Ed.), Cognitive behavior therapy and eating disorders (pp. 47-193). New York, NY: Guilford Press.

Fairburn, C.G., Marcus, M.D., \& Wilson, G.T. (1993). Cognitive-behavioral therapy for binge eating and bulimia nervosa: A comprehensive treatment manual. In C.G. Fairburn \& G.T. Wilson (Eds.), Binge eating: Nature, assessment, and treatment (pp. 361-404). New York, NY: Guilford Press. 
Fairburn, C.G., Norman, P.A., Welch, S.L., O'Connor, M.E., Doll, H.A., \& Peveler, R.C. (1995). A prospective study of outcome in bulimia nervosa and the long-term effects of three psychological treatments. Archives of General Psychiatry, 52, 304-312.

Fairchild, H., \& Cooper, M. (2010). A multidimensional measure of core beliefs relevant to eating disorders: Preliminary development and validation. Eating Behaviors, 11, 239-246.

Fedoroff, I.D., Polivy, J., \& Herman, C.P. (1997). The effect of pre-exposure to food cues on the eating behavior of restrained and unrestrained eaters. Appetite, 28, 33-47.

Fedoroff, I., Polivy, J., \& Herman, C.P. (2003). The specificity of restrained versus unrestrained eaters' responses to food cues: General desire to eat, or craving for the cued food? Appetite, 41, 7-13.

Garner, D.M., \& Bemis, K.M. (1982). A cognitive-behavioral approach to anorexia nervosa. Cognitive Therapy and Research, 6, 123-150.

Grilo, C.M., Shiffman, S., \& Carter-Campbell, J.T. (1994). Binge eating antecedents in normalweight nonpurging females: is there consistency? International Journal of Eating Disorders, 16, 239-249.

Hay, P. (2013). A systematic review of evidence for psychological treatments in eating disorders: 2005-2012. International Journal of Eating Disorders, 46, 462-469.

Hay, P.J., Mond, J., Buttner, P., \& Darby, A. (2008). Eating disorder behaviors are increasing: Findings from two sequential community surveys in South Australia. PLoS ONE, 3, e1541.

Haedt-Matt, A.A., \& Keel, P.K. (2011). Revisiting the affect regulation model of binge eating: A meta-analysis of studies using ecological momentary assessment. Psychological Bulletin, 137, 660-681.

Heatherton, T.F., \& Baumeister, R.F. (1991). Binge eating as escape from self-awareness. Psychological Bulletin, 110, 86-108.

Herman, C.P., \& Mack, D. (1975). Restrained and unrestrained eating. Journal of Personality, 43, 647-660.

Herman, C.P., \& Polivy, J. (1988). Restraint and excess in dieters and bulimics. In K.M. Pirke, D. Ploog, \& W. Vandereycken (Eds.), The psychobiology of bulimia nervosa (pp. 33-41). Berlin, Germany: Springer.

Herman, C.P., Polivy, J., \& Esses, V.M. (1987). The illusion of counter-regulation. Appetite, 9, 161-169.

Holmes, M., Fuller-Tyszkiewicz, M., Skouteris, H., \& Broadbent, J. (2015). Understanding the link between body image and binge eating: A model comparison approach. Eating and Weight Disorders-Studies on Anorexia, Bulimia and Obesity, 20, 81-89.

Iacovino, J.M., Gredysa, D.M., Altman, M., \& Wilfley, D.E. (2012). Psychological treatments for binge eating disorder. Current Psychiatry Reports, 14, 432-446.

Kessler, R.C., Berglund, P.A., Chiu, W.T., Deitz, A.C., Hudson, J.I., Shahly, V., ... Xavier, M. (2013). The prevalence and correlates of binge eating disorder in the World Health Organization World Mental Health Surveys. Biological Psychiatry, 73, 904-914.

Killen, J.D., Taylor, C.B., Hayward, C., Haydel, K.F., Wilson, D.M., Hammer, L., ... Strachowski, D. (1996). Weight concerns influence the development of eating disorders: a 4-year prospective study. Journal of Consulting and Clinical Psychology, 64, 936-940.

Knight, L.J., \& Boland, F.J. (1989). Restrained eating: An experimental disentanglement of the disinhibiting variables of perceived calories and food type. Journal of Abnormal Psychology, 98, 412-420.

Lacey, J. (1986). Pathogenesis. In L.J. Downey \& J.C. Malkin (Eds.), Current approaches: Bulimia nervosa (pp. 17-26). Southhampton, UK: Duphar.

Lammers, M.W., Vroling, M.S., Ouwens, M.A., Engels, R.C., \& Strien, T. (2015). Predictors of outcome for cognitive behaviour therapy in binge eating disorder. European Eating Disorders Review, 23, 219-228.

Lampard, A.M., Byrne, S.M., McLean, N., \& Fursland, A. (2011). An evaluation of the enhanced cognitive-behavioural model of bulimia nervosa. Behaviour Research and Therapy, 49, 529-535. 
Lavender, J.M., Wonderlich, S.A., Engel, S.G., Gordon, K.H., Kaye, W.H., \& Mitchell, J.E. (2015). Dimensions of emotion dysregulation in anorexia nervosa and bulimia nervosa: A conceptual review of the empirical literature. Clinical Psychology Review, 40, 111-122.

Leehr, E.J., Krohmer, K., Schag, K., Dresler, T., Zipfel, S., \& Giel, K.E. (2015). Emotion regulation model in binge eating disorder and obesity - A systematic review. Neuroscience $\mathcal{E}$ Biobehavioral Reviews, 49, 125-134.

Leung, N., Thomas, G., \& Waller, G. (2000). The relationship between parental bonding and core beliefs in anorexic and bulimic women. British Journal of Clinical Psychology, 39, 205-213.

Masley, S.A., Gillanders, D.T., Simpson, S.G., \& Taylor, M.A. (2012). A systematic review of the evidence base for schema therapy. Cognitive Behaviour Therapy, 41, 185-202.

McIntosh, V.V., Jordan, J., Carter, J.D., Frampton, C.M., McKenzie, J.M., Latner, J.D., \& Joyce, P.R. (2016). Psychotherapy for transdiagnostic binge eating: A randomized controlled trial of cognitive-behavioural therapy, appetite-focused cognitive-behavioural therapy, and schema therapy. Psychiatry Research, 240, 412-420.

McManus, F., \& Waller, G. (1995). A functional analysis of binge-eating. Clinical Psychology Review, $15,845-863$.

Mitchison, D., Hay, P., Slewa-Younan, S., \& Mond, J. (2014). The changing demographic profile of eating disorder behaviors in the community. BMC Public Health, 14, 943.

Munsch, S., Meyer, A.H., Quartier, V., \& Wilhelm, F.H. (2012). Binge eating in binge eating disorder: A breakdown of emotion regulatory process? Psychiatry Research, 195, 118-124.

Padesky, C.A., \& Greenberger, D. (1995). Clinician's guide to mind over mood. New York, NY: Guilford Press.

Paxton, S.J., \& Diggens, J. (1997). Avoidance coping, binge eating, and depression: An examination of the escape theory of binge eating. International Journal of Eating Disorders, 22, 83-87.

Pennesi, J.L., \& Wade, T.D. (2016). A systematic review of the existing models of disordered eating: Do they inform the development of effective interventions? Clinical Psychology Review, 43, 175192.

Picot, A.K., \& Lilenfeld, L.R. (2003). The relationship among binge severity, personality psychopathology, and body mass index. International Journal of Eating Disorders, 34, 98-107.

Polivy, J. (1996). Psychological consequences of food restriction. Journal of the American Dietetic Association, 96, 589-592.

Polivy, J., Heatherton, T.F., \& Herman, C.P. (1988). Self-esteem, restraint, and eating behavior. Journal of Abnormal Psychology, 97, 354-356.

Polivy, J., \& Herman, C.P. (1985). Dieting and binging: A causal analysis. American Psychologist, 40, 193-201.

Polivy, J., \& Herman, C.P. (1993). Etiology of binge eating: Psychological mechanisms. In C.G. Fairburn (Ed.), Binge eating: Nature, assessment and treatment (pp. 173-205). New York, NY: Guilford Press.

Poulsen, S., Lunn, S., Daniel, S.I., Folke, S., Mathiesen, B.B., Katznelson, H., \& Fairburn, C.G. (2014). A randomized controlled trial of psychoanalytic psychotherapy or cognitive-behavioral therapy for bulimia nervosa. American Journal of Psychiatry, 171, 109-116.

Pritchard, B.J., Bergin, J.L., \& Wade, T.D. (2004). A case series evaluation of guided self-help for bulimia nervosa using a cognitive manual. International Journal of Eating Disorders, 36, $144-156$.

Pugh, M. (2015). A narrative review of schemas and schema therapy outcomes in the eating disorders. Clinical Psychology Review, 39, 30-41.

Root, M.P., \& Fallon, P. (1989). Treating the victimized bulimic: The functions of binge-purge behavior. Journal of Interpersonal Violence, 4, 90-100.

Russell, G. (1979). Bulimia nervosa: an ominous variant of anorexia nervosa. Psychological Medicine, 9, 429-448.

Safer, D.L., Telch, C.F., \& Agras, W.S. (2001a). Dialectical behavior therapy adapted for bulimia: A case report. International Journal of Eating Disorders, 30, 101-106. 
Safer, D.L., Telch, C.F., \& Agras, W.S. (2001b). Dialectical behavior therapy for bulimia nervosa. American Journal of Psychiatry, 158, 632-634.

Shapiro, J.R., Berkman, N.D., Brownley, K.A., Sedway, J.A., Lohr, K.N., \& Bulik, C.M. (2007). Bulimia nervosa treatment: A systematic review of randomized controlled trials. International Journal of Eating Disorders, 40, 321-336.

Stice, E. (2001). A prospective test of the dual-pathway model of bulimic pathology: Mediating effects of dieting and negative affect. Journal of Abnormal Psychology, 110, 124-135.

Stice, E. (2002). Risk and maintenance factors for eating pathology: A meta-analytic review. Psychological Bulletin, 128, 825-848.

Stice, E. (2016). Interactive and mediational etiologic models of eating disorder onset: Evidence from prospective studies. Annual Review of Clinical Psychology, 12, 359-381.

Stice, E., \& Agras, W.S. (1998). Predicting onset and cessation of bulimic behaviors during adolescence: A longitudinal grouping analysis. Behavior Therapy, 29, 257-276.

Stice, E., Chase, A., Stormer, S., \& Appel, A. (2001). A randomized trial of a dissonance-based eating disorder prevention program. International Journal of Eating Disorders, 29, 247-262.

Stice, E., Killen, J.D., Hayward, C., \& Taylor, C.B. (1998). Age of onset for binge eating and purging during late adolescence: a 4-year survival analysis. Journal of Abnormal Psychology, 107, 671-675.

Stice, E., Marti, C.N., Rohde, P., \& Shaw, H. (2011). Testing mediators hypothesized to account for the effects of a dissonance-based eating disorder prevention program over longer term follow-up. Journal of Consulting and Clinical Psychology, 79, 398-405.

Stice, E., Presnell, K., \& Spangler, D. (2002). Risk factors for binge eating onset in adolescent girls: A 2-year prospective investigation. Health Psychology, 21, 131-138.

Stice, E., Shaw, H., \& Nemeroff, C. (1998). Dual pathway model of bulimia nervosa: Longitudinal support for dietary restraint and affect-regulation mechanisms. Journal of Social and Clinical Psychology, 17, 129-149.

Striegel-Moore, R.H., Dohm, F., Solomon, E., Fairburn, C., Pike, K., \& Wilfley, D. (2000). Subthreshold binge eating disorder. International Journal of Eating Disorders, 27, 270-278.

Svaldi, J., Griepenstroh, J., Tuschen-Caffier, B., \& Ehring, T. (2012). Emotion regulation deficits in eating disorders: A marker of eating pathology or general psychopathology? Psychiatry Research, 197, 103-111.

Telch, C.F., \& Agras, W.S. (1996). Do emotional states influence binge eating in the obese? International Journal of Eating Disorders, 20, 271-279.

Telch, C.F., Agras, W.S., \& Linehan, M.M. (2001). Dialectical behavior therapy for binge eating disorder. Journal of Consulting and Clinical Psychology, 69, 1061-1065.

Telch, C.F., \& Stice, E. (1998). Psychiatric comorbidity in women with binge eating disorder: Prevalence rates from a non-treatment-seeking sample. Journal of Consulting and Clinical Psychology, $66,768-776$.

Unoka, Z., Tölgyes, T., Czobor, P., \& Simon, L. (2010). Eating disorder behavior and early maladaptive schemas in subgroups of eating disorders. The Journal of Nervous and Mental Disease, 198, $425-431$.

Van Strien, T., Engels, R.C., Van Leeuwe, J., \& Snoek, H.M. (2005). The Stice model of overeating: Tests in clinical and non-clinical samples. Appetite, 45, 205-213.

Waller, G. (2002). The psychology of binge eating In C.G. Fairburn \& K.D. Brownell (Eds.), Eating disorders and obesity: A comprehensive handbook (pp. 98-102). New York, NY: Guilford Press.

Waller, G. (1993). Why do we diagnose different types of eating disorder? Arguments for a change in research and clinical practice. European Eating Disorders Review, 1, 74-89.

Waller, G. (2003). Schema-level cognitions in patients with binge eating disorder: A case control study. International Journal of Eating Disorders, 33, 458-464.

Waller, G., Dickson, C., \& Ohanian, V. (2002). Cognitive content in bulimic disorders: Core beliefs and eating attitudes. Eating Behaviors, 3, 171-178. 
Waller, G., Meyer, C., \& Ohanian, V. (2001). Psychometric properties of the long and short versions of the Young Schema Questionnaire: Core beliefs among bulimic and comparison women. Cognitive Therapy and Research, 25, 137-147.

Waller, G., Ohanian, V., Meyer, C., \& Osman, S. (2000). Cognitive content among bulimic women: The role of core beliefs. International Journal of Eating Disorders, 28, 235-241.

Waters, A., Hill, A., \& Waller, G. (2001). Bulimics' responses to food cravings: Is binge-eating a product of hunger or emotional state? Behaviour Research and Therapy, 39, 877-886.

Wells, A. (1993). Cognitive therapy of anxiety disorders: A practice manual and conceptual guide. Hoboken, NJ: John Wiley \& Sons.

Wilfley, D.E., Friedman, M.A., Dounchis, J.Z., Stein, R.I., Welch, R.R., \& Ball, S.A. (2000). Comorbid psychopathology in binge eating disorder: Relation to eating disorder severity at baseline and following treatment. Journal of Consulting and Clinical Psychology, 68, 641-649.

Wilfley, D.E., Welch, R.R., Stein, R.I., Spurrell, E.B., Cohen, L.R., Saelens, B.E., ... Matt, G.E. (2002). A randomized comparison of group cognitive-behavioral therapy and group interpersonal psychotherapy for the treatment of overweight individuals with binge-eating disorder. Archives of General Psychiatry, 59, 713-721.

Wilfley, D.E., Wilson, G.T., \& Agras, W.S. (2003). The clinical significance of binge eating disorder. International Journal of Eating Disorders, 34(S1), S96-S106.

Williamson, D.A., White, M.A., York-Crowe, E., \& Stewart, T.M. (2004). Cognitive-behavioral theories of eating disorders. Behavior Modification, 28, 711-738.

Wilson, G.T. (2002). Eating disorders and addictive disorders. In G. Fairburn \& K.D. Brownell (Eds.), Eating disorders and obesity: A comprehensive handbook (pp. 199-203). New York, NY: Guilford Press.

Wilson, G.T., Fairburn, C.C., Agras, W.S., Walsh, B.T., \& Kraemer, H. (2002). Cognitive-behavioral therapy for bulimia nervosa: Time course and mechanisms of change. Journal of Consulting and Clinical Psychology, 70, 267-274.

Wilson, G.T., Grilo, C.M., \& Vitousek, K.M. (2007). Psychological treatment of eating disorders. American Psychologist, 62, 199-216.

Wilson, G.T., \& Shafran, R. (2005). Eating disorders guidelines from NICE. The Lancet, 365(9453), 79-81.

Wonderlich, S.A., Peterson, C.B., Crosby, R.D., Smith, T.L., Klein, M.H., Mitchell, J.E., \& Crow, S.J. (2014). A randomized controlled comparison of integrative cognitive-affective therapy (ICAT) and enhanced cognitive-behavioral therapy (CBT-E) for bulimia nervosa. Psychological Medicine, $44,543-553$.

Young, E., \& Cooper, M. (2013). Applying a cognitive model to binge eating in a female community sample. Eating Behaviors, 14, 295-298.

Young, J.E. (1994). Cognitive therapy for personality disorders: A schema-focused approach. Sarasota, FL: Professional Resource Press.

Young, J.E., \& Brown, G. (1994). Young schema questionnaire. In J.E. Young (Ed), cognitive therapy for personality disorders: A schema-focused approach (pp. 63-76). Sarasota, FL: Professional Resource Press. 